\title{
Immigrant Crime and Legal Status: Evidence from Repeated Amnesty Programs
}

\author{
Francesco Fasani *†
}

April 16, 2018

\begin{abstract}
Do general amnesty programs lead to reductions in the crime rate among immigrants? We answer this question by exploiting cross-sectional and time variation in the number of immigrants legalized generated by the enactment of repeated amnesty programs between 1990 and 2005 in Italy. We address the potential endogeneity of the "legalization treatment" by instrumenting the actual number of legalized immigrants with alternative predicted measures based on past amnesty applications patterns and residential choices of documented and undocumented immigrants. We find that, in the year following an amnesty, regions in which a higher share of immigrants obtained legal status experienced a greater decline in non-EU immigrant crime rates, relative to other regions. The effect is statistically significant but relatively small and not persistent. In further results, we fail to find any evidence of substitution in the criminal market from other population groups - namely, EU immigrants and Italian citizens - and we observe a small and not persistent reduction in total offenses.
\end{abstract}

JEL Codes: F22, J61, K37

Keywords: illegal migration, legalization, migration policy

*School of Economics and Finance - Queen Mary University of London, $C R \mathrm{e} A M$ - Centre for Research and Analysis of Migration, CEPR and IZA. Email: f.fasani@qmul.ac.uk

${ }^{\dagger}$ I am especially grateful to Tommaso Frattini, Marco Tonello and Mathis Wagner for their comments and suggestions. The paper also benefitted from feedback received from participants at: 9th International Conference on Migration and Development, EUI Fiesole; 13th Annual Migration Meeting (AM), Bonn; Workshop on Immigration, Science Po. I would like to thank Paolo Buonanno for sharing his migration data with me. Financial assistance from the Fondazione Debenedetti (www.frdb.org) is gratefully acknowledged. The usual disclaimer applies. 


\section{Introduction}

Native residents in receiving countries generally perceive undocumented immigrants as a particularly unsettling presence. Data from recent waves of the Transatlantic Trends Survey on Immigration reported in Figure 1 show how attitudes of respondents in selected OECD countries vary when they consider undocumented (on the vertical axis) rather than documented immigrants (on the horizontal axis). The graph in panel A shows that the share of respondents concerned about undocumented immigrants is well above 50 percent in all countries and substantially larger than the share concerned about documented immigrants. Italy, the country we study in this paper, has the largest percentage of interviewees that are concerned about unauthorized immigrants (86 percent) while only 27 percent of Italian respondents report concern about legal foreign residents. The graph in panel B shows that in countries such as Italy, Spain and the US - where a large presence of unauthorized immigrants is a well documented fact - the vast majority of respondents believe that their foreign born population is predominantly undocumented. Further, Panel $\mathrm{C}$ shows that in all countries, the fraction of respondents reporting that undocumented immigrants are a burden on social services is larger than those casting such blame on documented immigrants. Similarly, panel D shows that the concern about immigrants increasing crime rates in host societies is stronger for unauthorized residents than for legal ones.

One of the reasons that may explain why undocumented immigrants are met with stronger opposition among receiving societies is that their presence tends to be associated with lawbreaking behavior. Individuals who circumvented migration legislation rules, so the argument goes, may be more prone to ignore legislation in general, including criminal law. As a matter of fact, theoretical predictions on the relationship between legal status and criminal behavior are ambiguous. Establishing whether legal status causally affects criminal choices is an empirical challenge. Undocumented immigrants often have demographic characteristics - e.g., being younger, less educated, more likely to be male than their documented counterparts - that 
strongly increase their likelihood of being potential offenders. A simple comparison of immigrants with and without legal status is not informative of causal relationships unless one can convincingly deal with endogenous selection into residence status. ${ }^{1}$ Existing causal evidence is still limited but tend to suggest that newly legalized crimes have lower propensity to engage in crime (Mastrobuoni and Pinotti, 2015, Pinotti, 2017).

The existence of crime reduction effects of legalization is relevant for the debate on policy interventions to deal with unauthorized residents. Voters' support for policies that offer pathways to legalization for undocumented immigrants may be strengthened if similar interventions lead to a sizeable and persistent drop in immigrant crime. Alternative types of programs, however, may produce different effects, depending on factors such as the criteria imposed for granting legal status, the type and size of migrant groups affected or the entitlements associated to legal status. General amnesties are a prominent example of these policies, having been adopted in several host countries in recent years (Casarico et al., forthcoming). As the current migration policy debate in the US highlights, amnesties generally spark an intense political debate. Whereas proponents emphasize the economic benefits stemming from offering legal status to unauthorized residents, opponents often fear a recall effect on new-comers and generally dislike the idea of openly rewarding law-breaking behaviour. We still know very little on the effects of general amnesties on immigrant crime. ${ }^{2}$ If amnesties are effective in reducing criminal behaviour among immigrants, this may provide an additional argument for policy makers that support them. ${ }^{3}$

In our paper, we analyze a context in which the undocumented population is large and

\footnotetext{
${ }^{1}$ Unobservable characteristics may increase both the probability of being undocumented and the propensity to commit crime if, for instance, undocumented immigrants are more impatient or less risk averse than documented immigrants.Dustmann et al. (2017) study the impact of legal status on the consumption behavior of immigrants and find evidence compatible with less risk averse individuals sorting into illegal residence status.

${ }^{2}$ Evidence on the effect of alternative migration policy interventions on immigrant crime is also extremely scarce. To the best of our knowledge, the only exception is the study by Miles and Cox (2014) on internal enforcement against undocumented immigrants and crime rates in the US.

${ }^{3} \mathrm{~A}$ few papers have theoretically analyzed benefits and costs of amnesties, focusing in particular on the effects on the labour market and public finances in receiving countries. See, among others: (Chau, 2001; Epstein and Weiss, 2011; Casarico et al., forthcoming, Machado, 2017)
} 
persistent and where amnesty programs have been repeatedly and frequently enacted. In particular, we exploit four general amnesties, which granted legal status to large fractions of the undocumented immigrant population in Italy, and we empirically investigate whether legalizations were followed by significant reductions in the crime rate among immigrants and how persistent this effect was. Our identification strategy relies on both the geographical variation in the number of immigrants legalized in different Italian regions and the time variation generated by the repeated programs. We address the potential endogeneity of the "legalization treatment" by instrumenting the actual number of legalized immigrants with alternative predicted measures based on past residential choices of documented and undocumented immigrants and on applications patterns in previous amnesties. We find that, in the year following an amnesty, regions in which a higher share of immigrants obtained legal status experienced a greater decline in immigrant crime rates, relative to other regions. The effect is statistically significant but relatively small in magnitude and not persistent. In further results, we fail to find evidence of substitution in the criminal market from other population groups (EU immigrants and Italian citizens) whose residence status was not directly affected by amnesties. Moreover, we find that the total number of offenses decreased more in areas that legalized a higher number of undocumented immigrants, although the effect is small and not persistent. Our findings suggest that although many other good arguments can be advanced to support amnesties for unauthorized residents, their crime-reducing impact does not seem to be a compelling one.

The paper is organized as follows. In section 2, we briefly summarize related literature on immigration, legal status and crime. Section 3 describes the Italian institutional setting, focusing on amnesties and on immigrants' involvement in criminal activities. Section 4 offers a discussion of our data and some descriptive statistics. Identification issues and our empirical strategy are explained in section 5. Estimation results are presented in section 6. Finally, some concluding remarks are made in section 7 . 


\section{Legal Status and Crime: Theory and Evidence}

The empirical literature on the effects of legal status on immigrants' outcomes in the labor market generally finds increased wages and returns to skills for newly legalized immigrants. ${ }^{4}$ If obtaining legal status improves immigrants' economic integration, a standard economic model of criminal decisions à la Becker (Becker, 1968) would predict a reduction in their propensity to engage in crime. However, if a criminal conviction implies harsher penalties for undocumented immigrants than for legal residents - e.g. being deported from the host country or being permanently barred from applying for legal residence status in the future - legalizations may produce the opposite effect. ${ }^{5}$ The impact of legal status on immigrants' crime rate is therefore theoretically ambiguous. A growing body of evidence has analyzed the relationship between the presence of immigrants and crime rates in receiving societies. ${ }^{6}$ More recently, a few studies have focused on the causal impact of changes in legal status on immigrants' criminal decisions by exploiting policies that created arguably exogenous variation in legal status. Using Italian prison records, Mastrobuoni and Pinotti (2015) rely on the 2007 European Union Enlargement to compare recidivism rates of inmates from new EU member countries and candidate member countries in a difference-in-differences approach. Pinotti (2017), instead, exploits the Italian quota system using a regression discontinuity design and looks at successful and unsuccessful applicant for residence and working permits. Both papers find a sizeable reduction in propensity to engage in crime of newly legalized immigrants.

If individuals who become legal residents have lower incentives to engage in crime, one may conclude that general amnesties that take a large fraction of the undocumented population "out of the shadows" should potentially be effective policy instruments to reduce immigrant crime. The validity of this conclusion, however, is subject to a few important caveats.

\footnotetext{
${ }^{4}$ See Fasani (2015) for a recent review of this literature.

${ }^{5}$ For instance, applicants for IRCA legalization were not admissible if they had previously been convicted of a felony or of three or more misdemeanors (Kerwin, 2010).

${ }^{6}$ This literature has examined both the US (Butcher and Piehl, 1998a b. Borjas et al. 2010, Chalfin, 2014.

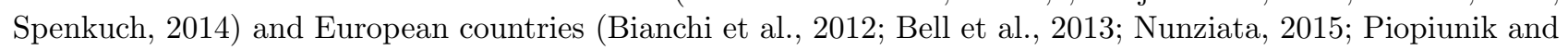
Ruhose, 2017), providing mixed evidence.
} 
First, the overall effect of an amnesty on immigrant crime will depend on the impact produced on all groups of migrants: those who were already legal residents, the legalized ones, those who remained undocumented and the new arrivals. For instance, an amnesty may reduce the crime rate of those who are successfully legalized while increasing the propensity to engage in crime of those who failed to become legal residents. Indeed, this latter group will see its prospects of being legalized becoming increasingly uncertain and being delayed until the next legalization opportunity (if any), with potentially adverse effects of the incentives to commit crime. Moreover, legalization programs may be accompanied by general equilibrium effects and/or by changes in enforcement policies that may induce a deterioration of the labour market outcomes of immigrants who remain undocumented. In the US context, Freedman et al. (forthcoming) find that Hispanic citizens - who were arguably still undocumented after the 1986 IRCA amnesty expired - offended significantly more. They rationalize their results with the IRCA reform having introduced employment restrictions that made it more difficult for newly arrived undocumented immigrants to find a job in the US.

A second important aspect to be considered is the presence of substitution effects in the criminal market. If amnesties reduce the crime supply of a segment of the immigrant population but leave the demand for crime unaffected, crime opportunities that are not taken by the newly legalized immigrants may be seized by other groups of the migrant population and/or by native offenders. Overall crime rates may thus remain unchanged even if legalized immigrants do less crime.

Third, the size and duration of the crime-reducing effect of amnesties will also depend on how effective legalizations are in reducing the presence of illegal residents in the country. While legalizing (part of) the existing stock of undocumented residents, amnesties can at the same time attract new unauthorized arrivals, potentially lured by the prospect of benefitting from the current or a future amnesty. This "recall effect" may be particularly strong if the enactment of the amnesty generates the expectation that other amnesties will be granted in the future. ${ }^{7}$

\footnotetext{
${ }^{7}$ As we will see in section 3.1 , this should be a major concern in a context, such as the Italian one, in which
} 
If newly legalized immigrants are immediately replaced by unauthorized newcomers, the crimereducing effect of the amnesty may be zero even in the short run. In any case, the amnesty effect will last only as long as new inflows do not reconstitute the initial stock of unauthorized immigrants in the host country.

Our paper investigates how effective general amnesties are in reducing total immigrant crime rates. The closest paper to ours is Baker (2015): he studies the impact of the 1986 IRCA amnesty program on total (native and immigrant) crime and finds a significant crime-reduction effect. We expand on his analysis in several directions. First, rather than a one-off amnesty that offered a pathway to citizenship, we consider a setting in which repeated general amnesties have been enacted within a limited span of time and have granted just a temporary resident status to legalized immigrants. Second, we develop an instrumental variable strategy to deal with the potential endogeneity of legalizations. Third, we separately analyze crime committed by different groups of immigrants and by natives, allowing us to study potential substitution effects in the criminal market. Fourth, we study a different OECD country in which the presence of undocumented immigrants has been equally persistent and pervasive in recent years.

\section{$3 \quad$ Institutional Setting}

\subsection{Migration Policy and Amnesties in Italy}

Figure 2 summarizes the evolution of the foreign-born population in Italy between 1986 and 2012. The continuous line shows the stock of legal residents: it grew from fewer than 0.5 million in 1990 to approximately 3.6 million individuals in 2012, that is, from less than 1 percent to approximately 6 percent of the total resident population. General amnesties have been a constant feature of the Italian migration policy. Between 1986 and 2012, seven legalization programs were enacted to grant legal status to the growing undocumented foreign-born population amnesties are routinely enacted. In the US context, instead, Orrenius and Zavodny (2003) show that the 1986 IRCA did not increase nor decrease long-term patterns of the inflow of unauthorized immigrants. 
residing in Italy. The vertical bars in figure 2 report the number of immigrants legalized in each amnesty (in thousands): 105 in 1986, 218 in 1990, 244 in 1995, 217 in 1998, 637 in 2002, 295 in 2009 and 135 in 2012. Amnesties were decided by the central government and simultaneously implemented in all regions using nationally uniform procedures. They offered a temporary and renewable residence and working permit to all undocumented immigrants who satisfied specific criteria, generally based on a predetermined residence condition. ${ }^{8}$ The process of screening the applications and releasing the residence permits was generally concluded within one or two years from the closing date of the submission window. The acceptance rate of applications was extremely high, being above 90 percent for all four amnesties that we analyze in this paper (1990, 1995, 1998, 2002).

The dots in figure 2 correspond to estimates of the stock of unauthorized residents and show a distinctive roller-coaster trend. ${ }^{9}$ According to these estimates, amnesties managed to substantially reduce the stock of unauthorized residents in the short run, but failed to stem new inflows of undocumented newcomers that rapidly re-created this population after each amnesty. ${ }^{10}$ As a matter of fact, the frequent repetition of amnesties itself suggests that undocumented immigrants kept arriving in the country after each of the legalization program. Police records on border enforcement suggest that amnesties may have attracted larger inflows of undocumented immigrants. The continuous line in Figure 3 reports the total annual number of foreign citizens refused entry at the Italian border for being undocumented between 1989 and 2006 (vertical axis on the right). Although changes in this time series may be also driven by changes in enforcement, entry refusals are an arguably good proxy of unauthorized migratory

\footnotetext{
${ }^{8}$ The amnesties in 1986 and 1995 simply asked the applicant to prove they had been in Italy at least since the day before the amnesty law was passed. The amnesties in 1990 and 1998 required two and seven months of minimum residence in Italy, respectively. The subsequent amnesties (2002, 2009 and 2012) conditioned eligibility on both a residence and an employment condition. See Devillanova et al. (forthcoming).

${ }^{9}$ These estimates are produced in a systematic way and using a methodologically coherent approach by an independent research foundation called ISMU (Fasani, 2009).

${ }^{10}$ The observable drop between 2006 and 2007 is due to an exceptional decision of the Italian government to grant legal status to all applicants for the 2006 quota instead of rationing the working permits as the quota system would imply. That choice corresponded to a de-facto amnesty for more than 300 thousand undocumented workers (Fasani, 2009). Note that our empirical analysis focuses on the period 1991-2005 and it is therefore not affected by this particular policy event.
} 
pressure on the borders. They shows a downward trend over time - from around 60 thousand per year in the early '90s to 20-30 thousand in the early '00s - but also distinctive spikes in correspondence of the four amnesties. Remarkably, yearly growth rates in people refused entry at the border - reported by the bars in Figure 3 (vertical axis on the left) - are generally positive only in the years the amnesties took place.

\subsection{Immigrant Crime in Italy}

Figure 4 reports the time series of four indicators of immigrants' criminal involvement in Italy over the period 1991-2005 (criminal charges, convictions, prison entries and prison population). The distance between any of these continuous lines and the underlying dotted line - reporting the share of documented immigrants over the total resident population - highlights a striking over-representation of immigrants among criminal statistics at all stages of the Italian criminal justice system. In 2005, the documented immigrant share in the total population reached approximately 4 percent. In the same year, immigrants accounted for approximately 23 percent of individuals receiving a criminal charge and for 22 percent of criminals convicted in Italian tribunals. ${ }^{11}$ Figures are even higher in prison statistics: in 2005,45 percent of the individuals entering prison were immigrants, while they accounted for 33 percent of the prison population. Overall, figure 4 suggests that a troubling large fraction of the immigrant population is involved in crime in Italy. However, the fact that immigrants are often overrepresented among those demographic groups - i.e., male, young, low-educated and poor individuals - who are more likely to commit crime may contribute to inflating their criminal statistics. Moreover, one cannot rule out the possibility that the criminal justice system is biased against immigrants in Italy. ${ }^{12}$

Official records show that a large share of the immigrants committing crime in Italy are

\footnotetext{
${ }^{11}$ Even if we account for the estimated stock of 540 thousand undocumented immigrants who were residing in Italy in 2005, the total immigrant share would increase to 4.7 percent and immigrants would still be overrepresented among individuals receiving a criminal charge or a conviction by a factor of more than 4 .

${ }^{12}$ We are not aware of any rigourous study of discrimination against immigrants in the Italian criminal justice system. A closer examination of Italian prison statistics (ISTAT, 2006, 2012), however, suggests that factor like language barriers, poor legal assistance and lack of a legal domicile all concur to the over-representation of immigrants among the population behind bars in Italy.
} 
undocumented residents. ${ }^{13}$ This information is not collected in a systematic way and it is only available for criminal charges, at the national level and for some years (see Barbagli and A. 2011). In the period 2004-2009, the average share of illegal residents varies between 60 and 80 percent, depending on the type of offense: the highest average shares are in burglary (0.83), car theft $(0.82)$, theft $(0.78)$ and robbery $(0.77)$. This is a persistent phenomenon: figures recorded in the mid-1990s were very similar to those of the late 2000s.

A country where immigrants largely contribute to criminal statistics and where undocumented immigrants are responsible for the majority of these offenses provides an ideal setting for analyzing whether mass legalizations are an effective policy instrument for reducing immigrants' crime rates. ${ }^{14}$

\section{Data and Descriptive Statistics}

In our analysis, we use a panel of the twenty Italian administrative regions over fifteen years (1991-2005) and analyze the empirical relationship between regional crime rates of foreign-born citizens and the number of immigrants legalized in each region by one of the four amnesties that were enacted over this period.

Immigrant crime. Our main measure of immigrant crime is based on yearly records from the Italian Ministry of Justice on the number of individuals who received a criminal charge. Data are consistently available for the period 1991-2005 and are disaggregated by the region where the crime was committed and by the nationality of the (potential) offender. We use these records to construct the main outcome variables for our empirical analysis: the number of non-EU immigrants, EU immigrants and natives receiving a criminal charge. Unfortunately,

\footnotetext{
${ }^{13}$ Note that during the period we study, being an illegal resident was not a criminal offense in Italy but rather an administrative infraction. Apprehensions of immigrants lacking legal status, therefore, are not counted in criminal statistics.

${ }_{14}^{14}$ Bianchi et al. (2012) find no causal impact of the immigrant population on local crime rates. Although the authors attempt to control for the presence of undocumented migrants in several ways, the inherent mismeasurement of the distribution of this population across areas and of its movements over time may explain why their estimates suggest that immigrants do not cause crime to rise.
} 
these data cannot be further disaggregated by type of crime or by gender and the series was discontinued after year 2005. Criminal charges account for the subset of reported offences for which the cases were cleared by the police, that is, crimes for which a potential offender was identified and referred to the judical system to face prosecution. The identification of potential offenders implies that their nationality is recorded, making criminal charges a very informative indicator for studying the criminal behavior of immigrants. Statistics on reported crime, instead, lack any demographic information about the offenders since they are often unknown at the time the crime is reported to the police. While data on convictions and detainees - that generally have information on the nationality of the criminals - share the important drawbacks of capturing an even more selected subset of the criminal population and of having a substantial lag with respect to the moment the offense was committed. In order to develop an alternative measure of immigrant crime, we further gained access to yearly records from the Ministry of Internal Affairs on the number of immigrants arrested by the Italian police forces. ${ }^{15}$ These data can be disaggregated by region, are available for the period 1992-2001 and do not distinguish between EU and non-EU immigrants. Finally, the Italian Ministry of Justice data on criminal charges contain also information on the total number of offenses for which the Italian criminal justice system has initiated prosecution proceedings. These data are available with regional disaggregation and over the same period (1991-2005) as the dataset on individuals charged. The offenses data are not linked to specific offenders and cannot thus be attributed to immigrants rather than to natives. The information on the type of offense is also not available. We use these records to construct a measure of total regional crime.

Panel A in Table 1 reports some descriptive statistics for these variables. Over the period we consider (1991-2005), there were 10.7 non-EU immigrants charged per ten thousand population each year, with overall and within-region standard deviations of 9.2 and 6.3, respectively. Non-EU immigrants accounted for 12 percent of the individuals receiving a criminal charge, EU

\footnotetext{
${ }^{15}$ Note that individuals arrested and individuals receiving a criminal charge are both subsets of the total pool of offenders, but they only partially overlap: not all individuals being arrested are subsequently charged, and not all those receiving a criminal charge are also arrested.
} 
immigrants for one percent (with approximately one individual charged every year per ten thousand population), and the remaining 87 percent were Italian citizens. This latter population group had an annual average of approximately 83 individuals charged per ten thousand population. The average number of offenses was nearly 455 per ten thousand population, with overall and within-region standard deviations of 173 and 84, respectively. Further, approximately 8.4 immigrants per ten thousand population were arrested over the period 1992-2001.

Legalizations. Over the period we consider (1991-2005), three general amnesties were granted in Italy: in 1995, 1998 and 2002 (see section 3.1). In addition, an amnesty program was implemented in 1990, and its effects on crime may still be present at the beginning of the period we consider. Aggregate records on the total number of undocumented immigrants legalized in each region by each of these four amnesties were obtained from the Italian Ministry of Internal Affairs and used to construct our main independent variable. Panel B in Table 1 shows that the average number of immigrants legalized by amnesties over the whole period analyzed is approximately 12 individuals (per ten thousand population) with the overall and within-region standard deviation both being close to 30. This variable, however, includes many zero values in non-amnesty years. To obtain a better sense of the actual size of the "legalizations treatment", the table also reports descriptive statistics for the average number of legalizations computed exclusively in amnesty years. The average figure increases to approximately 45 immigrants legalized per ten thousand population, with a minimum value of 7.8 and a maximum of nearly 230.

Other regional controls. The other regional controls used in our analysis - resident population, employment rate, GDP per capita and documented immigrant population - are provided by the Italian Office of Statistics (ISTAT; www.istat.it). Over the period 1991-2005, the average region in our sample had a native population of 2.8 million people, a GDP per capita of 12.7 thousand euros (at constant 1990 euro-equivalent prices), an unemployment rate of 10.7 percent and approximately 185 documented immigrants per ten thousand native population (see panel C of Table 1). 


\section{Empirical Strategy}

\subsection{Estimating Equation}

Our main measure of immigrant crime is the number of non-EU immigrants receiving a criminal charge $\left(F B \_c h\right)$, while the legalizations variable $A_{r t}$ is the number of individuals legalized in each region by one of the four amnesties enacted between 1990 and 2005. We normalize both variables using the total native population residing in the region Pop rt (in tens of thousands), and we take logs. ${ }^{16}$ We regress changes in log regional migrant crime rate on the log of the (normalized) number of legalized immigrants: this latter variable captures amnesty-induced reductions in the regional undocumented population. Our main estimating equation is:

$$
\Delta \ln \left(\frac{F B_{-} c h_{r t}}{\text { Pop }_{r t}}\right)=\beta \ln \left(\frac{A_{r t}}{\text { Pop }_{r t}}\right)+\Delta X_{r t}^{\prime} \gamma+\Delta d_{t}+\Delta \varepsilon_{r t}
$$

where: $X_{r t}$ is a set of time-varying regional controls; $d_{t}$ are year dummies; $\varepsilon_{r t}$ is an error term. Any regional fixed effect that may be potentially correlated with both dependent and explanatory variables is removed by taking first-differences. The coefficient of interest $\beta$ identifies the elasticity of immigrant crime rate to the "legalization treatment" (i.e. the number of immigrants legalized). A negative coefficient would imply that regions where a higher number of immigrants gained legal status experienced a larger decline in immigrant crime.

Equation (1) specifies a contemporaneous relation between immigrant crime and legalization of undocumented immigrants. However, the timing and duration of this effect (if any) is an empirical question. As a matter of fact, the effect does not have to be immediate. As discussed in section 3.1, the applications processing time implied a sizeable lag between submission and the obtainment of legal status. If the migrants' incentives to engage in crime drop only once they become legal residents, the crime-reducing impact of amnesties may be observed only after

\footnotetext{
${ }^{16}$ Because natives may react to inflows of immigrants by moving to a different region, throughout the analysis we always use the first lag of the native population. Results do not significantly change if further lags or contemporaneous population are used.
} 
some time. Further, the time elapsing between the date the crime is committed and the date the criminal charge is filed may also generate a lag in the observed effect. In addition, the effect may be more or less persistent. As we argue in section 2, its duration depends on how the amnesty affects the criminal incentives of the different groups of the migrant population, their relative size and their growth rates. In our regression analysis, we will investigate and discuss the exact timing of the amnesty effect.

\subsection{Econometric Issues}

The elasticity of immigrant crime with respect to legalizations can be consistently estimated only if the number of immigrants legalized in each region is exogenous in the regression equation (1). Amnesties are enacted by the central government and simultaneously implemented in all regions. While the decision to grant amnesties and the timing of these political decisions are arguably orthogonal to immigrants' endogenous residential choices and to local regional shocks, the number of legalized individuals in each region may be correlated with both types of variables. None of the amnesties we consider had a predetermined national or regional cap on the total number of immigrants who could be legalized. The share of applicants who were granted legal status was generally above 90 percent. The number of immigrants legalized in each region, therefore, closely followed the number of applications submitted. Amnesty applications are determined by the residential choices of undocumented immigrants and by their decisions to participate in the program. Both types of choice are potentially endogenous in our regression. For instance, undocumented immigrants will have greater incentive to settle in areas that offer them better labor market opportunities and to apply in regions where returns to having legal status are higher. Therefore, we could expect to observe more (less) applications in regions with higher (lower) employment rates. Insofar as higher employment translates into lower crime rates, a cross-sectional analysis would suggest that regions that receive higher numbers of amnesty applications tend to experience lower levels of crime. Our empirical analysis is 
robust to this identification threat because we remove any persistent regional difference by first-differencing our data and exploiting within-region variation over time in legalizations and crime. One may nevertheless be concerned that immigrants are (at least partially) able to anticipate future shocks to the local economy and to modify their residential choices and/or their participation in amnesties according to their predictions. For instance, if undocumented immigrants who expect to observe an increase in employment in one region in the next period are more likely to move there and to apply for legal status, and if a positive shock to employment induces a reduction in crime, we could observe that a higher numbers of applications is filed in regions experiencing larger reductions in crime rates. In this case, removing regional fixed effects would not be sufficient to identify a causal parameter. In addition, one cannot rule out the existence of other time-varying unobservable variables that correlate with both the outcome and our main dependent variable and that could bias our estimate of the parameter $\beta$. Unobservable changes in the strictness of regional police enforcement against undocumented immigrants, for instance, may influence both their presence and their crime involvement in a region. ${ }^{17}$

We address these concerns in two ways. First, we include time-varying regional controls to capture the local economic cycle that is potentially correlated with both crime rates and the number of applications. Second, we instrument the actual number of legalized immigrants with alternative predicted measures based on past location choices of immigrants and past amnesty application decisions of undocumented immigrants. ${ }^{18}$

Our main instrument predicts the number of legalizations in each region $r$ in each amnesty year $t\left(\widehat{A}_{r t}^{81}\right)$ taking the total number of immigrants from each source country $c$ legalized during each amnesty $\left(A_{c t}\right)$ and allocating them across regions according to the distribution of

\footnotetext{
${ }^{17}$ Potential (but minor) empirical issues regarding the other regional controls included in our regressions are discussed in section A.2 in the Online Appendix.

${ }^{18}$ Our empirical strategy partially resembles the approach adopted by Barbarino and Mastrobuoni (2014). They estimate the impact of changes in the prison population on crime and exploit repeated collective pardons that generate exogenous variation in the number of detained criminals. While they can observe both the prison population and the number of pardoned inmates (and can thus instrument the former variable with the latter), we only observe the number of legalized immigrants and not the population of undocumented immigrants.
} 
immigrants recorded in the 1981 census $\left(\overline{s h}_{c r}^{81}\right):{ }^{19}$

$$
\widehat{A}_{r t}^{81}=\sum_{c} \overline{s h}_{c r}^{81} * A_{c t} \quad \text { for } t=(1990,1995,1998,2002)
$$

We define $\overline{s h}_{c r}^{81}$ as the ratio between the number of immigrants from country $c$ residing in region $r$ in year $1981\left(M_{c r}^{81}\right)$ and the number of immigrants from country $c$ residing in Italy in year $1981\left(M_{c}^{81}\right)$ :

$$
\overline{s h}_{c r}^{81}=\frac{M_{c r}^{81}}{M_{c}^{81}}
$$

The instrument has two components: a set of constant shares $\overline{s h}_{c r}^{81}$, which generate crosssectional variation, and a national flow variable $A_{c t}$, which varies over time. ${ }^{20}$ The exogeneity of the instrument with respect to regional shocks is ensured by the fact that the first component is predetermined with respect to the period analyzed (the census took place ten years before the beginning of the period under study, namely 1991-2005) while the second component is measured at the national level and should thus not reflect shocks occurring in any particular Italian region. The instrument is valid under the identifying assumption that - conditional on regional fixed effects - the shocks that occurred in year 1981 (and before) and determined the distribution of immigrants of different nationalities across regions in that year are not systematically correlated with those that determined the distribution of applications in the amnesties granted in 1990, 1995, 1998 or 2002. This seems a reasonable assumption. Records on the first twenty nationalities of immigrants legalized in each amnesty are available for all four programs in the period we study. Data are reported in Online Appendix Table A 1 . Countries of origin like Morocco, Tunisia, Philippines, China and Senegal were consistently placed among

\footnotetext{
${ }^{19}$ Note that the census survey captures all immigrants who are residing in the country, including undocumented immigrants, although the data do not allow to distinguish immigrants by their legal status.

${ }^{20}$ This instrument is conceptually similar to the supply-push component instrument proposed by Altonji and Card (1991) and, since then, widely used in the migration literature. In studying the impact of immigrants on local crime rates, for instance, this IV approach has been adopted by both Bianchi et al. (2012) for Italy and Bell et al. (2013) for the UK. The instrument relies on a large body of evidence showing that settlement patterns of previous waves of immigrants are strong predictors of residential choices of following waves (see, among others, Bartel, 1989 and Munshi, 2003).
} 
the top national groups in all amnesties. Other nationalities, especially Eastern European ones, appeared only in the mid-90s and quickly reached the top of the ranking. These data are used to measure the time varying component $A_{c t}$ of our instrument. The distribution of immigrants in $1981\left(\overline{s h}_{c r}^{81}\right)$ is measured with 1981 census data that are available at the regional level but only for national groups of immigrants that were predominant at the time. ${ }^{21}$

In order to test the robustness of our estimates to the use of alternative instruments, we develop two additional IV strategies. The first instrumental variable is constructed using information on a wider set of nationalities of immigrants who resided in Italy in 1990, while the second is based on the geographical distribution of applications for an amnesty program that was enacted in 1986. Both instruments are described in section A.1 in the Online Appendix.

An additional potential source of endogeneity that should be considered is measurement. Using official administrative records for each amnesty program we should just have some unsystematic measurement error in our independent variable. Indeed, mistakes in the recording practices may lead to under- or over-counting of the actual number of legalized immigrants in certain instances. This classical measurement error would generate attenuation bias in the coefficient of interest but it would be effectively dealt with by using our proposed IV strategy. ${ }^{22}$

Two empirical issues regarding the outcome variable also deserve some discussion. First, a possible disadvantage of using data on criminal charges (and arrests) is that observed changes in crime may be driven by changes in the criminal justice systems treatment of immigrants rather than by actual changes in their underlying criminal activity. ${ }^{23}$ Although we cannot completely rule out this possibility, we do not see particular reasons for expecting systematic changes in policing practices after the amnesties in Italy. In any case, these changes would

\footnotetext{
${ }^{21}$ Beyond EU-15 nationals, the main national groups residing in Italy in 1981 were (in decreasing order): Tunisia, Jugoslavia, Iran, Libya, Venezuela, Argentina, Egypt, Ethiopia, Philippines, Brazil, Chile, Morocco, Cape Verde, Somalia and Algeria.

${ }^{22}$ Measurement issues, instead, would potentially be far more complex if one wanted to use amnesty legalizations as a proxy for changes in the underlying undocumented population.

${ }^{23}$ Bohn et al. (2015) report some evidence in this direction for misdemeanors (but not for felonies) in one American county in the aftermath of the IRCA.
} 
bias our results only if policing behavior changed differently across regions and in a way that is systematically correlated with the number of immigrants legalized in each region. A second issue to be considered is the role played by migrants' reporting behavior. If immigrants' decision to report a crime is influenced by their residence status, we may expect amnesties to change the number or reported offenses even if the underlying number of committed crimes does not change. $^{24}$

\section{$6 \quad$ Results}

\subsection{OLS and IV Results}

OLS estimates. In Table 2, we investigate whether legalizations are associated with lower immigrant crime and the exact timing and duration of this empirical relationship. Following our estimating equation (1), we regress the yearly change in the log of non-EU immigrants charged with a criminal offense (per ten thousand population) on the log of the number of individuals legalized (per ten thousand population) in each amnesty. ${ }^{25}$ In all regressions, regional fixed effects are removed by taking first-differences, a full set of year dummies is included to capture national trends, and standard errors are clustered at the regional level to allow for within-region serial correlation in local shocks. ${ }^{26}$ In columns 1-4 of Table 2, we alternatively include the contemporaneous value of the "legalization treatment", its first and second lags and its first lead. The estimates reported in these columns show that while contemporaneous legalizations do not result in lower immigrant crime (column 1), the first lag of the "legalization

\footnotetext{
${ }^{24}$ It is reasonable to expect undocumented immigrants to be more wary of interacting with the police than documented immigrants. Gaining legal status should thus increase their incentives to report crimes, as found by Comino et al. (2016) for the IRCA amnesty in the US. If this behavioral response is in place and is sufficiently strong, it would potentially attenuate any crime-reduction effect of amnesties that we may observe. Unfortunately, available data do not allow us to empirically asses this issue in our context.

${ }^{25}$ The number of immigrants legalized $\left(A_{r t}\right)$ takes positive values in amnesty years and is equal to zero otherwise. In order to have defined values when taking logs, we have added one to the number of applicants in all years when constructing our main dependent variable: $\ln \left[\left(A_{r t}+1\right) / P_{o p} p_{r t}\right]$.

${ }^{26}$ In Online Appendix Table A 2, we use wild cluster bootstrap to address the concern that twenty cluster may be too few to obtain consistent estimates of the standard errors. The level of significance of our estimates is preserved. See section A.3 in the Online Appendix for further discussion.
} 
treatment" produces a significant negative effect (column 2): the estimated coefficient on this latter variable is minus 0.03 and significant at the five percent level. The estimated coefficient on the second lag of legalization is close to zero and not significant (column 3). Similarly, legalizations in period $(t+1)$ do not produce any significant effect on current crime rates. In the following columns (column 5-9), we gradually include all of the "legalization treatment" variables plus time-varying regional controls (log of total native population, log of GDP per capita, unemployment rate, log of documented immigrant share). In all specifications, the estimated coefficient on legalizations in (t-1) remains negative and statistically significant, while the coefficients on the other legalization variables are closer to zero and not statistically different from it. The estimates in Table 2 strongly suggest that regions where larger shares of immigrants were legalized experienced relatively larger reductions in the number of immigrants receiving a criminal charge. The crime-reducing effect is not contemporaneous, becoming significant only one year after the amnesty took place. This finding is fully consistent both with the delays of amnesty programs in actually granting legal status to the applicants and with criminal charges measuring changes in committed offenses with some lag. ${ }^{27}$ The estimates in Table 2 further imply that the effect is not persistent: two years after legalization, we fail to find any significant effect on immigrant crime. A non-significant coefficient is also found on the first lead of the "legalization treatment". Note that while establishing the precise timing of the legalization treatment after the amnesty is a purely empirical question, finding a significant effect (of any sign) of legalizations on crime before the amnesty took place would be difficult to reconcile with a causal interpretation of the relationship between legalizations and immigrant crime. Or, it would point at the existence of anticipation effects.

In panel A of Table 3, we test the sensitivity of the estimated coefficient on legalizations in period $(t-1)$ to the gradual inclusion of controls and of different national and local trends.

\footnotetext{
${ }^{27}$ Data on the average lag between the time a crime is committed and the moment the police files a criminal charge against someone - or arrests a potential offender - are not available for the period we study. According to a recent report of the Italian Office of National Statistics (ISTAT, 2017), however, the vast majority of criminal charges $(81 \%)$ filed by the Italian police in year 2014 referred to crimes committed in the same year.
} 
Beginning with a specification in which we condition only on year dummies (column 1), we add regional controls in column 2 (log of total native population, log of GDP per capita, unemployment rate) and the (log of the) documented immigrants share in column 3. We follow the same pattern in columns 4-6, but we now include in the first-differenced equation dummies for the four Italian macro-areas (North-West, North-East, Central, South) to allow for macroarea linear trends. Finally, in columns 7-9, we allow for any trend at the macro-area level by conditioning on a full set of interactions between year dummies and macro-area dummies. The estimated coefficient on the "legalization treatment" in ( $t-1)$ oscillates around minus 0.03 and is significant across all specifications. ${ }^{28}$ In Panel B of Table 3, we test whether our findings are robust to the use of alternative measures of immigrant crime. In panel B1, the outcome is the yearly change in the number of non-EU immigrants charged with a criminal offense normalized by the total number of individuals receiving a criminal charge (rather than by the resident native population). In panel B2, we use data on the number of immigrants arrested in each region by the Italian police, normalized by the total native population. The coefficients reported in panels B1 and B2 of Table 3 show that a negative and significant effect of legalizations on immigrant crime (in the following period) is estimated with both measures. ${ }^{29}$

IV estimates. Our OLS estimates suggest that legalizations generate a statistically significant crime reduction effect. As discussed in section 5.2, however, these estimates may be biased by the potential endogeneity of the "legalization treatment". In Table 4, we report IV estimates - obtained using our main instrument $\left(\widehat{A}_{r t}^{81}\right)$ - for the three alternative measures of immigrant crime. Controls and trends are gradually included in the regressions following the same pattern

\footnotetext{
${ }^{28}$ In the Online Appendix Table A 3, we report OLS estimates for the other regional controls: we find positive and significant coefficients on both the regional unemployment rate and documented immigrant share. The first relationship suggests that worse economic conditions increase immigrants' propensity to engage in crime, and this is consistent with a standard criminal choice model $\grave{a}$-la-Becker and with the fact that immigrants are generally particularly exposed to economic downturns (Dustmann et al., 2010). The second coefficient mechanically captures the fact that having more foreign-born residents leads to having more immigrants involved in crime. Both coefficients identify economically sizeable effects.

${ }^{29}$ In unreported regressions, we test the timing of the legalizations effect on the number of immigrants arrested. The pattern is remarkably similar to that observed for criminal charges and reported in table 2, whereby a significant effect is estimated exclusively in the year after the amnesty took place.
} 
as in Table 3. In all specifications, the instrument is a strong predictor of the actual number of immigrants legalized, with an F-statistic ( $I V:$ F-stat) that is well above the rule-of-thumb value of ten for weak instruments. For our main measure of immigrant crime (Panel A), the IV estimates of the coefficient on the number of legalizations at time $t-1$ are all negative and significantly different from zero. Notably, they are also very similar in magnitude to the corresponding OLS estimates in Table 3. Indeed, we use a cluster-robust version of the Hausman test and find little evidence of endogeneity. ${ }^{30}$ IV results obtained using our alternative IV strategies are shown in Panel A in the Online Appendix Table A 4: they are extremely similar to those obtained using our main instrument. Further, panel B in Table 4 reports IV estimates for the two alternative measures of immigrant crime: the share of non-EU immigrants receiving a criminal charge over the total number of individuals charged (panel B1) and the number of immigrants arrested per ten thousand native population (panel B2)). These IV estimates are also very similar to the OLS estimates reported in panel B of Table 3 .

Magnitude. Our estimates unambiguously confirm that legalizing undocumented immigrants produces a crime-reducing effect in the year following the amnesty. The estimated coefficient on the "legalization treatment" implies that a one-percent increase in the number of legalizations (per ten thousand population) leads to an approximately 0.03 percent reduction in the ratio of immigrants charged in year $t$ over those charged in year $t-1$. A more intuitive interpretation of our results is obtained by taking our variables at their mean values and computing the impact of legalizing, for instance, ten more immigrants per ten thousand population. According to Table 1, increasing $A_{r t} /$ Pop $_{r t}$ by ten units corresponds to an approximately 80 percent increase with respect to its mean value (12.1) and to a change equal to roughly one third of its withinregion standard deviation (28.8). In a region where immigrant crime is at its mean value (10.7

\footnotetext{
${ }^{30}$ The standard form of the Hausman test assumes homoscedasticity and no within-group serial correlation. As we always cluster the standard errors by region, we implement a modified Hausman test that is robust to clustering, as proposed in Wooldridge (2002). We include the predicted residuals from the first-stage regression as an additional control in the main OLS equation and test whether the estimated coefficient on this variable is significantly different from zero. See Cameron and Miller (2015) for details. In all columns, the p-values reported in Panel A of Table 4 (IV: Hausman test: p-value) imply that we fail to reject the null hypothesis of the exogeneity of the "legalization treatment".
} 
immigrants charged per ten thousand population; see Table 1), legalizing ten more immigrants (per ten thousand population) would lead to having nearly 0.24 fewer immigrants charged with criminal offenses (per ten thousand population). The average yearly change in the number of immigrants charged in our sample is 1.2 (per ten thousand population): a region that legalized ten more immigrants (per ten thousand population) would therefore experience a yearly change in immigrant crime that is 20 percent smaller than the average change in our sample. The effect is economically small although not completely negligible.

\subsection{Further Results and Robustness Checks}

Natives and EU immigrants. Table 5 reports OLS estimation results of the impact of amnesties on criminal charges against Italian citizens (Panel A) and EU immigrants (Panel B). Over the period we study, natives accounted for the largest share of individuals charged (87 percent) while EU immigrants accounted for only one percent of them (see section 4). Regional controls and dummies for alternative national and regional trends are gradually included in the specification. As the residence status of Italian and EU citizens is not affected by amnesties, these two population groups should not be directly affected by the legalization programs. This set of estimates can thus be interpreted as a falsification exercise: we do not expect to find that regions where a larger number of non-EU immigrants obtained legal status experienced a reduction in crime committed by these other two population groups. Substitution effects in the criminal market, however, may take place. If amnesties reduce the crime supply but leave crime demand unaffected, the criminal opportunities that are no longer taken by the legalized immigrants could be seized by other groups of potential offenders. The estimation results reported in Table 5 show no significant effect of legalizations on the number of individuals who received a criminal charge among these two populations. The coefficients are all close to zero, and none of them is significant. IV results - shown in the Online Appendix Table A 5- fully support this set of findings. 
Total offenses. If the reduction in non-EU immigrant crime was not matched by a change of the opposite sign in the crime rate of EU immigrants and/or natives, we should expect to observe a decline in overall crime rates. In Table 6, we test this conjecture by estimating the impact of legalizations on total offenses rather than on the number of individuals receiving a criminal charge. As with the previous outcomes, we normalize the number of offenses by total native population (in tens of thousands) and we take logs. OLS (Panel A) and IV estimates (Panel B) are reported in Table 6. All OLS coefficients are negative, although not significant. The IV estimates are slightly larger in size and some of them - especially when year times macro-area dummies are included - are significant or marginally significant. ${ }^{31}$ Although the coefficients are imprecisely estimated, these estimates suggest an overall crime-reducing effect of amnesties. As expected from the fact that the effect on immigrant crime is economically small, the resulting effect on total offenses is also quite small in magnitude. ${ }^{32}$ In unreported regressions, we find that the effect is also not persistent.

Heterogeneity across areas. Our findings can be rationalized with legalizations reducing immigrants' incentives to engage in crime by improving their labor market prospects. If this is the mechanism at work, we should expect to observe a stronger effect of granting legal status in areas that offer more opportunities of finding a job in the formal labor market. We investigate this conjecture in Table 7. In the Italian context, North-West and North-east regions are significantly richer, have lower unemployment rates and smaller underground economies than Central and Southern regions. ${ }^{33}$ In columns 1-3, we interact the "legalization treatment" with a dummy for the northern region and with a dummy for the central and southern regions.

\footnotetext{
${ }^{31} \mathrm{IV}$ estimates are obtained using our main instrument $\widehat{A}_{r t}^{81}$. Estimates from the alternative IV strategies are reported in panel B of the Online Appendix Table A 4 and are remarkably similar to those in panel B of Table 6.

32 The IV coefficient on the "legalization treatment" is approximately minus 0.01. According to this estimate, a region that legalized ten more immigrants (per ten thousand population) - an increase roughly corresponding to 80 percent of the mean value of the legalization variable - would experience a 1 percent reduction in total offenses or 4.5 fewer offenses with respect to the mean value (that is 454.8; see Table 1).

${ }^{33}$ Over the period we analyze, the average GDP per capita was 16 thousand euros in the North-East, 15.7 in the North-West, 13.7 in Central Italy and 9.2 in the South and Islands. The average unemployment rate was 4.5, 6.3, 7.7 and 17.5 percent, respectively. The estimated shares of shadow employment were $9,10,13$ and 22 percent, respectively.
} 
In columns 4-6, we include interactions of legalizations with a dummy for each of the four Italian macro-areas (North-East, North-West, Central and South). Our estimates suggest that the crime reduction effect of legalization is indeed stronger in Northern regions. Similarly, Mastrobuoni and Pinotti (2015) find an effect of legal status on re-incarceration rates only in the North of Italy.

Spatial Analysis. Our empirical analysis is based on relatively large geographical units. Nevertheless, we may still worry that ignoring spatial lags or spatial dependence in the error term may lead to biased estimates or reduced efficiency, respectively (LeSage and Pace, 2009). In the Online Appendix Table A 6, we test for the presence of spatial autoregression or autocorrelation across regions and check whether our estimates are affected by takings these empirical aspects into consideration. Using alternative spatial weighting matrices, we estimate a Spatial Autoregressive Model (SAR) and a Spatial Error Model (SEM). We find that the spatial terms are generally not significant and that our estimates of the impact of legalizations on immigrant crime are not affected by including spatial terms in the specification. These findings suggest that spatial dependence is not relevant in our context. See section A.4 in the Online Appendix for further discussion.

Type of offenses. The regional records on criminal charges we use in this analysis cannot be further disaggregated by type of offense. Over the period we consider, national level data show that immigrants are predominantly charged for property crimes (more than $75 \%$ of the total). Existing evidence on crime and legal status - see Mastrobuoni and Pinotti (2015) and Pinotti (2017) for the Italian case - has consistently found that obtaining legal status reduce immigrants' incentives to engage in economically motivated crime while leaving violent crime unaffected. We replicate our empirical analysis using regional records on reported crime to the police. These data can be disaggregated by major types of offence, although they contain no information on potential offenders and, therefore, on their nationalities. In unreported regressions, we find that legalizations of undocumented immigrants lead to a reduction in some types of crimes in the year following the amnesty. In particular, we estimate a strongly significant reduction in 
robberies. ${ }^{34}$ In addition, we also find a marginally significant reduction in kidnap rate, a violent crime that is generally economically motivated.

\section{Conclusions}

In this paper, we test whether amnesty programs - that repeatedly granted legal status to large shares of the undocumented immigrant population in Italy - led to significant reductions in the immigrant crime rate. Our empirical analysis identifies a small and not persistent crimereducing effect of legalizations. When interpreting the magnitude of the effect we identify, one must bear in mind that our main dependent variable is total (non-EU) immigrant crime: if undocumented and/or documented immigrants increase their propensity to commit crime in response to the reduction in criminal activities of newly legalized immigrants, we would find a small effect of amnesties on aggregate immigrant crime even if the effect on those who obtained legal status were substantial. Moreover, the arrival of new inflows of undocumented immigrants may reduce the persistence and even nullify the potential crime-reducing impact of amnesty. In the Italian context, where amnesties have been frequently and repeatedly adopted and where the existing estimates of the undocumented immigrant stock in Italy suggest that this population rapidly regenerated after each amnesty, this is undoubtedly an important explanation for our findings. ${ }^{35}$

Our results suggest that, although there may be many other good reasons to grant legal residence status to unauthorized residents, policy-makers can hardly use the argument that mass legalizations produce an economically important crime-reducing effect. Rather than enacting one-off national programs, however, offering permanent opportunities for legalization for individuals satisfying certain criteria may be more effective in achieving the desired reduc-

\footnotetext{
${ }^{34}$ Remarkably, this finding directly relates to the evidence provided by Bianchi et al (2012). They study the relationship between immigration and crime in Italy over the period 1990-2003 and find that immigration increases only the incidence of robberies, producing no significant effect on any other type of crime.

${ }^{35}$ The observed amnesty crime-reduction effect may be also attenuated by changes in immigrants' crime reporting behavior (if legalized immigrants have a higher propensity to report offenses). See section 5.2 .
} 
tion in immigrant crime. Legalizations decided on an individual basis, indeed, may reduce the propensity to engage in crime of legalized individuals without generating sudden inflows of new unauthorized entrants. Moreover, individual legalizations do not generate the general equilibrium effects that a massive program implies and that may damage the economic prospects of immigrants who fail to obtain legal status (inducing them to engage in more crime). The disadvantage of these permanent schemes, however, is creating the expectation among immigrants that becoming a legal resident is possible for undocumented immigrants, potentially generating more unauthorized entries and longer residence duration among undocumented immigrants. Repeated and frequent amnesties have similar - and likely stronger - disadvantages and should therefore be considered the least desirable policy option in this regard. 


\section{References}

Altonji, J. J. and Card, D. (1991), The effects of immigration on the labor market outcomes of less-skilled natives, in J. M. Abowd and R. B. Freeman, eds, 'Immigration, Trade and Labor', University of Chicago Press.

Baker, S. (2015), 'Effects of immigrant legalization on crime', American Economic Review Papers and Proceedings 105(5), 210-13.

Barbagli, M. and A., C. (2011), Rapporto sulla criminalit e la sicurezza in italia 2010, Technical report, Italian Ministry of Internal Affairs.

Barbarino, A. and Mastrobuoni, G. (2014), 'The Incapacitation Effect of Incarceration: Evidence from Several Italian Collective Pardons', American Economic Journal: Economic Policy 6(1), 1-37.

Bartel, A. P. (1989), 'Where do the new u.s. immigrants live?', Journal of Labor Economics $7(4), 371-91$.

Becker, G. S. (1968), 'Crime and punishment: An economic approach', The Journal of Political Economy 76(2), 169-217.

Bell, B., Fasani, F. and Machin, S. (2013), 'Crime and immigration: Evidence from large immigrant waves', The Review of Economics and Statistics 95(4), 1278-1290.

Belotti, F., Hughes, G. and Piano Mortari, A. (2017), 'Spatial panel-data models using stata', Stata Journal 17(1), 139-180(42).

Bertrand, M., Duflo, E. and Mullainathan, S. (2004), 'How Much Should We Trust DifferencesIn-Differences Estimates?', The Quarterly Journal of Economics 119(1), 249-275.

Bianchi, M., Buonanno, P. and Pinotti, P. (2012), 'Do immigrants cause crime?', Journal of the European Economic Association 10(6), 1318-1347. 
Bohn, S., Freedman, M. and Owens, E. (2015), 'The criminal justice response to policy interventions: Evidence from immigration reform', American Economic Review - Papers and Proceedings 105(5), 214219.

Borjas, G. J., Grogger, J. and Hanson, G. H. (2010), 'Immigration and the Economic Status of African-American Men', Economica 77(306), 255-282.

Butcher, K. F. and Piehl, A. M. (1998a), 'Cross-city evidence on the relationship between immigration and crime', Journal of Policy Analysis and Management 17(3), 457-493.

Butcher, K. F. and Piehl, A. M. (1998b), 'Recent immigrants: Unexpected implications for crime and incarceration', Industrial and Labor Relations Review 51(4), 654-679.

Cameron, A. C., Gelbach, J. B. and Miller, D. L. (2008), 'Bootstrap-Based Improvements for Inference with Clustered Errors', The Review of Economics and Statistics 90(3), 414-427.

Cameron, A. C. and Miller, D. L. (2015), 'A practitioner's guide to cluster-robust inference', Journal of Human Resources 50(2), 317-373.

Casarico, A., Facchini, G. and Frattini, T. (forthcoming), 'What drives the legalization of immigrants? evidence from irca', Regional Science and Urban Economics .

Chalfin, A. (2014), 'What is the contribution of mexican immigration to u.s. crime rates? evidence from rainfall shocks in mexico', American Law and Economics Review 16(1), 220268.

Chau, N. H. (2001), 'Strategic amnesty and credible immigration reform', Journal of Labor Economics 19(3), 604-34.

Comino, S., Mastrobuoni, G. and Nicol, A. (2016), Silence of the Innocents: Illegal Immigrants' Underreporting of Crime and their Victimization, IZA Discussion Papers 10306, Institute for the Study of Labor (IZA). 
Devillanova, C., Fasani, F. and Frattini, T. (forthcoming), 'Employment of undocumented immigrants and the prospect of legal status: Evidence from an amnesty program', Industrial and Labor Relations Review .

Drukker, D. M., Peng, H., Prucha, I. and Raciborski, R. (2013), 'Creating and managing spatial-weighting matrices with the spmat command', Stata Journal 13(2), 242-286.

Dustmann, C., Fasani, F. and Speciale, B. (2017), 'Illegal migration and consumption behavior of immigrant households', Journal of the European Economic Association 15(3), 654-691.

Dustmann, C., Frattini, T. and Preston, I. P. (2013), 'The effect of immigration along the distribution of wages', The Review of Economic Studies 80(1), 145-173.

Dustmann, C., Glitz, A. and Vogel, T. (2010), 'Employment, wages, and the economic cycle: Differences between immigrants and natives', European Economic Review 54(1), 1-17.

Epstein, G. and Weiss, A. (2011), 'The why, when, and how of immigration amnesties', Journal of Population Economics 24(1), 285-316.

Fasani, F. (2009), A country report on undocumented migration in italy, Technical report, CLANDESTINO - Undocumented Migration: Counting the Uncountable - Data and Trends Across Europe.

Fasani, F. (2015), 'Understanding the role of immigrants' legal status: Evidence from policy experiments', CESifo Economic Studies 61(3-4), 722-763.

Freedman, M., Owens, E. and Bohn, S. (forthcoming), 'Immigration, employment opportunities, and criminal behavior', American Economic Journal - Economic Policy .

ISTAT (2006), Gli stranieri e il carcere: aspetti della detenzione, Technical report, ISTAT.

ISTAT (2012), I detenuti nelle carceri italiane - anno 2011, Technical report, ISTAT. 
ISTAT (2017), Delitti, imputati e vittime dei reati. una lettura integrata delle fonti sulla criminalità e giustizia, Technical report, ISTAT.

Kerwin, D. M. (2010), More than irca: Us legalization programs and the current policy debate, Policy brief, Migration Policy Institute.

LeSage, J. P. and Pace, R. K. (2009), Introduction to Spatial Econometrics, London: CRC Press, Taylor and Francis Group.

Machado, J. (2017), 'Dealing with undocumented immigrants: the welfare effects of amnesties and deportations', Journal of Demographic Economics 83(4), 445-492.

Mastrobuoni, G. and Pinotti, P. (2015), 'Legal status and the criminal activity of immigrants', American Economic Journal: Applied Economics 7(2), 175-206.

Miles, T. J. and Cox, A. B. (2014), 'Does immigration enforcement reduce crime? evidence from secure communities', Journal of Law and Economics 57(4), 937 - 973.

Munshi, K. (2003), 'Networks in the modern economy: Mexican migrants in the u. s. labor market', The Quarterly Journal of Economics 118(2), 549-599.

Nunziata, L. (2015), 'Immigration and crime: evidence from victimization data', Journal of Population Economics 28(3), 697-736.

Orrenius, P. and Zavodny, M. (2003), 'Do amnesty programs reduce undocumented immigration? Evidence from Irca', Demography 40(3), 437-450.

Pinotti, P. (2017), 'Clicking on heaven's door: The effect of immigrant legalization on crime', American Economic Review 107(1), 138-68.

Piopiunik, M. and Ruhose, J. (2017), 'Immigration, regional conditions, and crime: Evidence from an allocation policy in germany', European Economic Review 92, 258 - 282. 
Spenkuch, J. L. (2014), 'Understanding the impact of immigration on crime', American Law and Economics Review 16(1), 177-219.

Wooldridge, J. (2002), Econometric analysis of cross s ection and panel data, The MIT press. 


\section{Figures}

Figure 1: Concern About Documented and Undocumented Immigrants in Selected OECD Countries (Share of Respondents Agreeing with Each Statement)

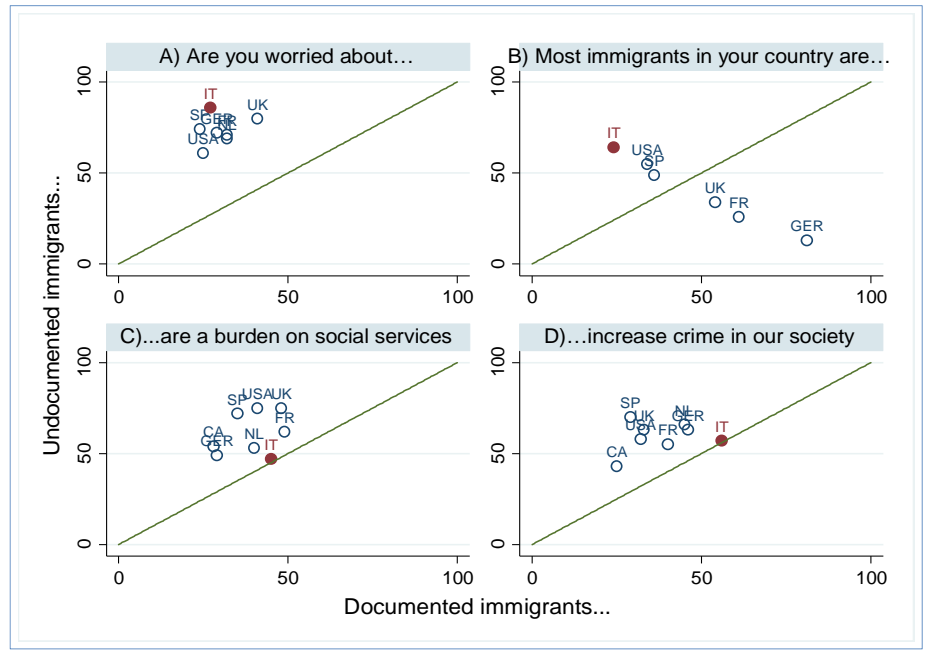

Source: Transatlantic Trends - Immigration 2010, 2011 and 2013.

Figure 2: Documented Immigrants, Undocumented Immigrants and Amnesties in Italy (Years 1986-2012)

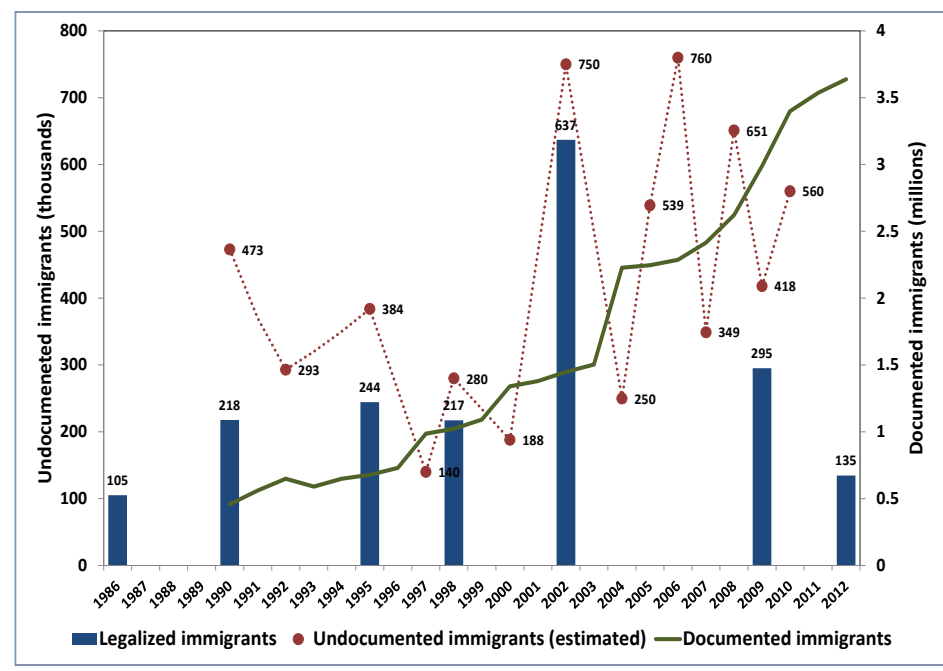

Note: the continuous line shows the stock of documented immigrants, as measured with the number of residence permits (right vertical axis); the dots are estimates of the stock of undocumented immigrants produced by ISMU (left vertical axis); the bars report the number of immigrants legalized in each amnesty program (left vertical axis). Source: elaborations from ISTAT and ISMU data. 
Figure 3: Foreign Citizens Refused Entry at the Border (Years 1986-2006)

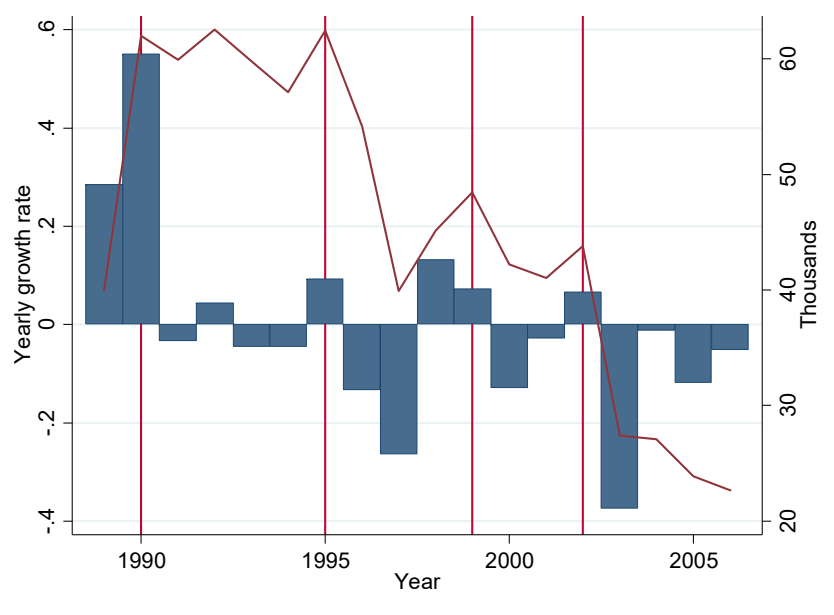

Note: the continuous line reports the total annual number of foreign citizens refused entry at the Italian border for being undocumented (right vertical axis); the bars report yearly growth rates in people refused entry at the border (left vertical axis); the vertical lines identify the four amnesties (1990, 1995, 1998, 2002) that took place in this period of time. Source: elaborations from data of the Italian Minister of Internal Affairs.

Figure 4: Share of Foreign Born Population at Different Stages of the Italian Criminal Justice Process (Years: 1991-2005)

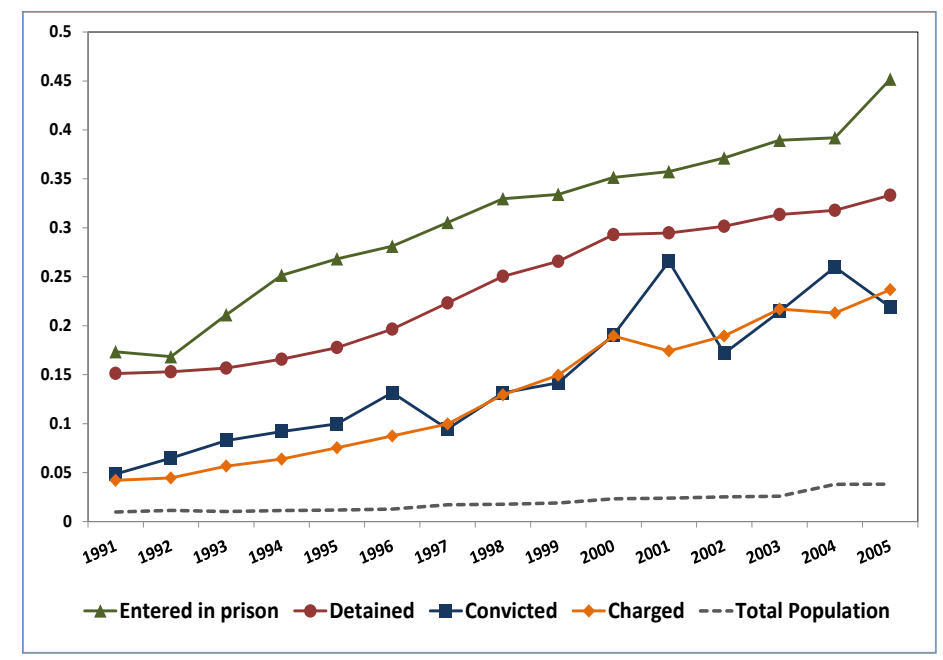

Note: Elaborations from data of the Italian Minister of Internal Affairs and Minister of Justice. 


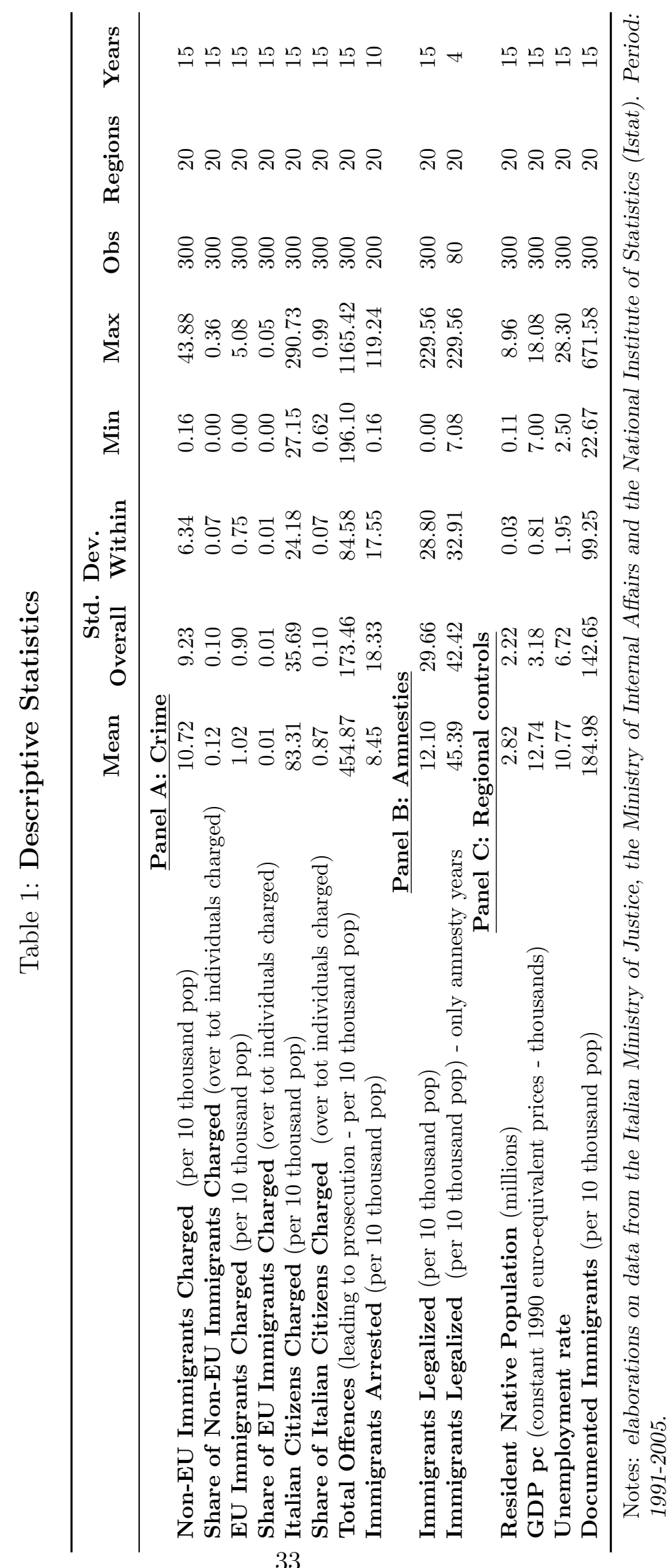




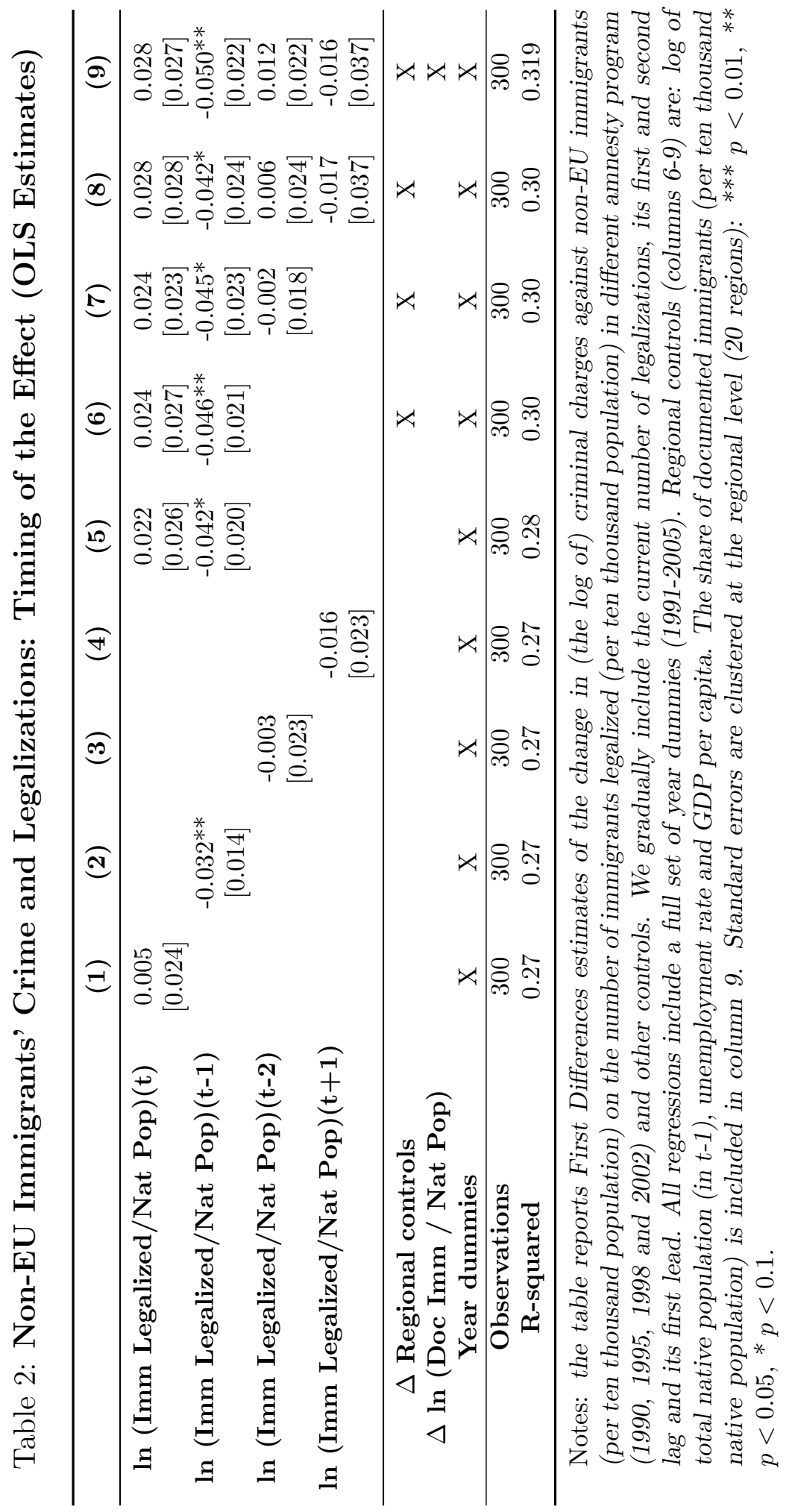




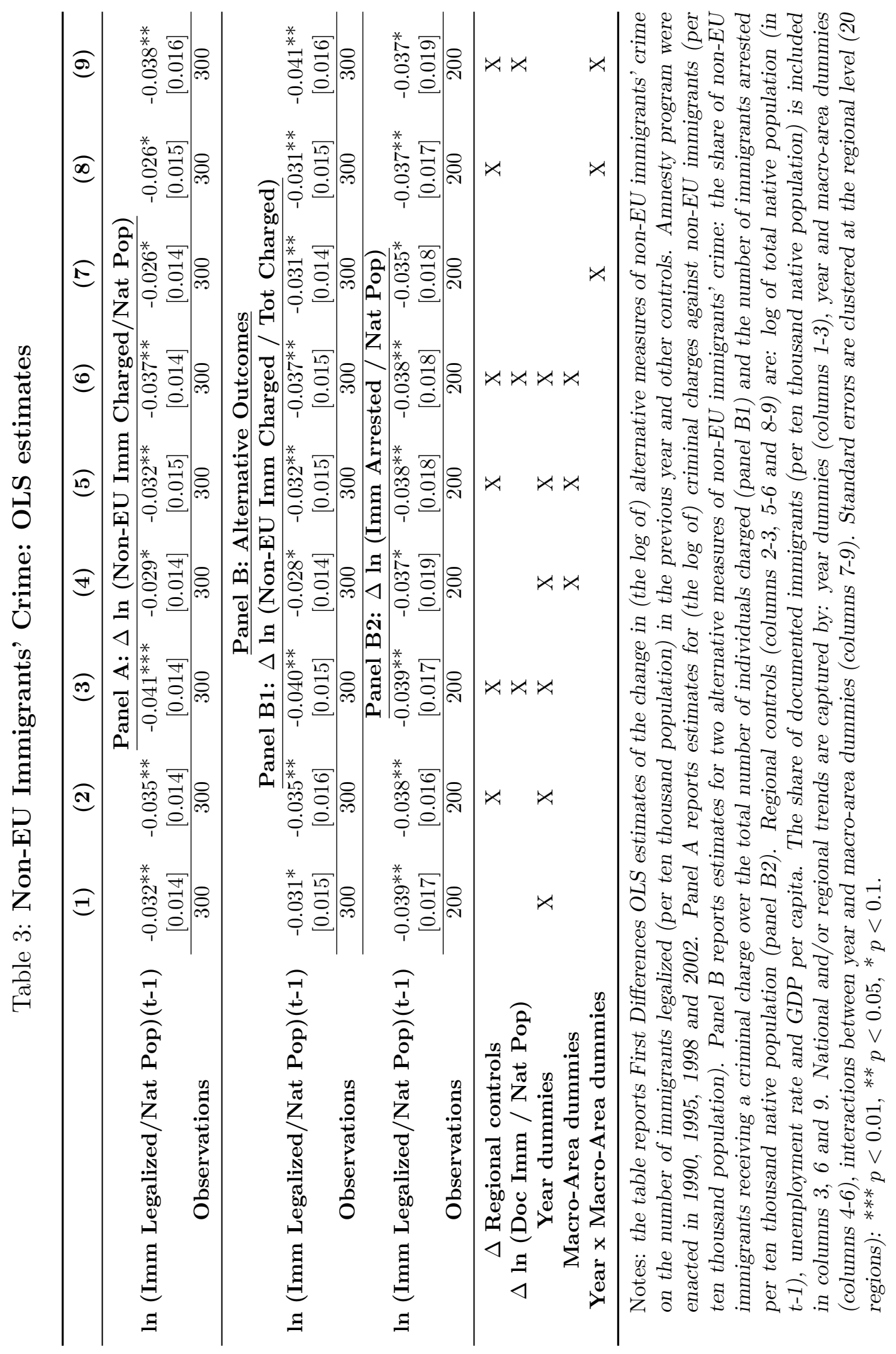




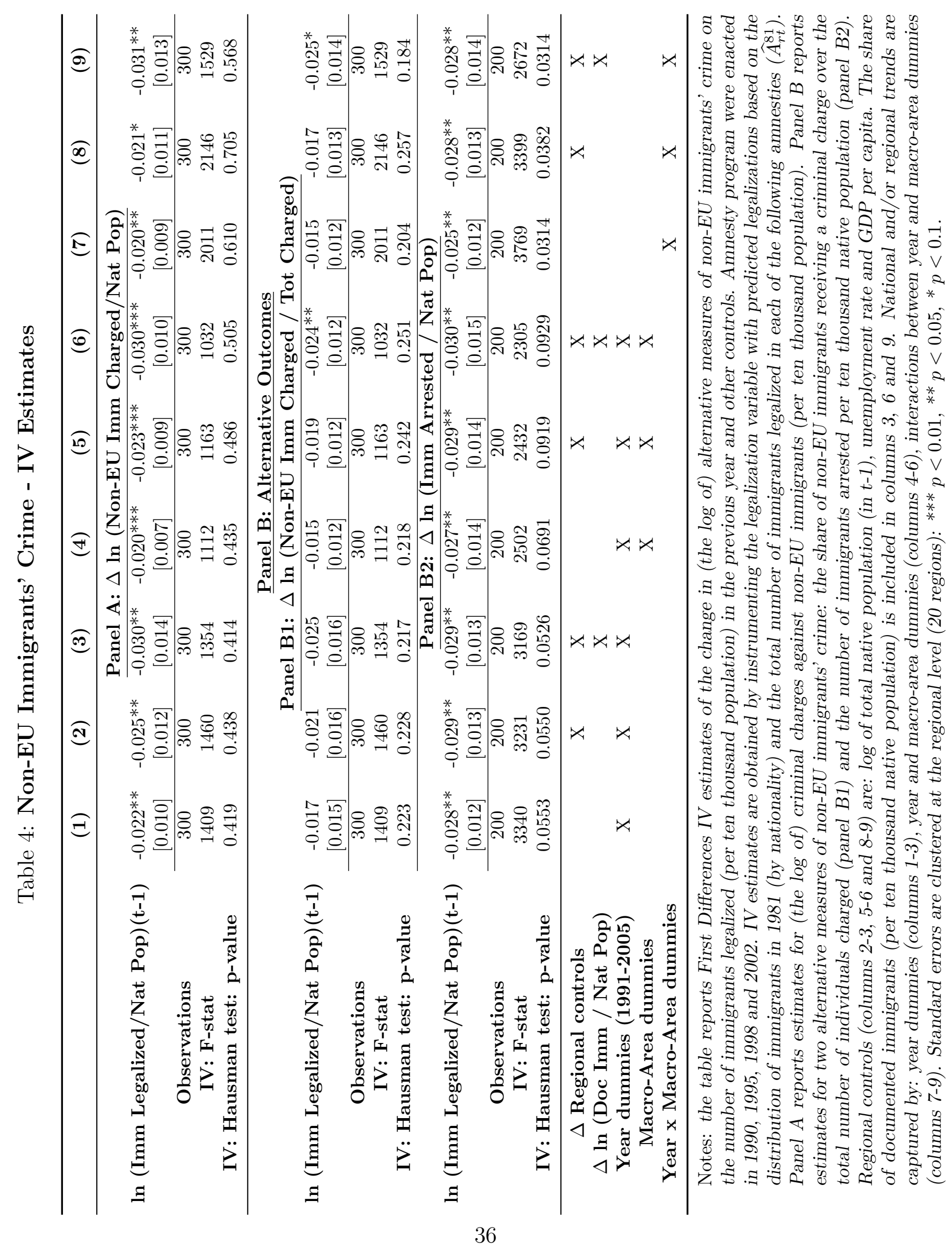




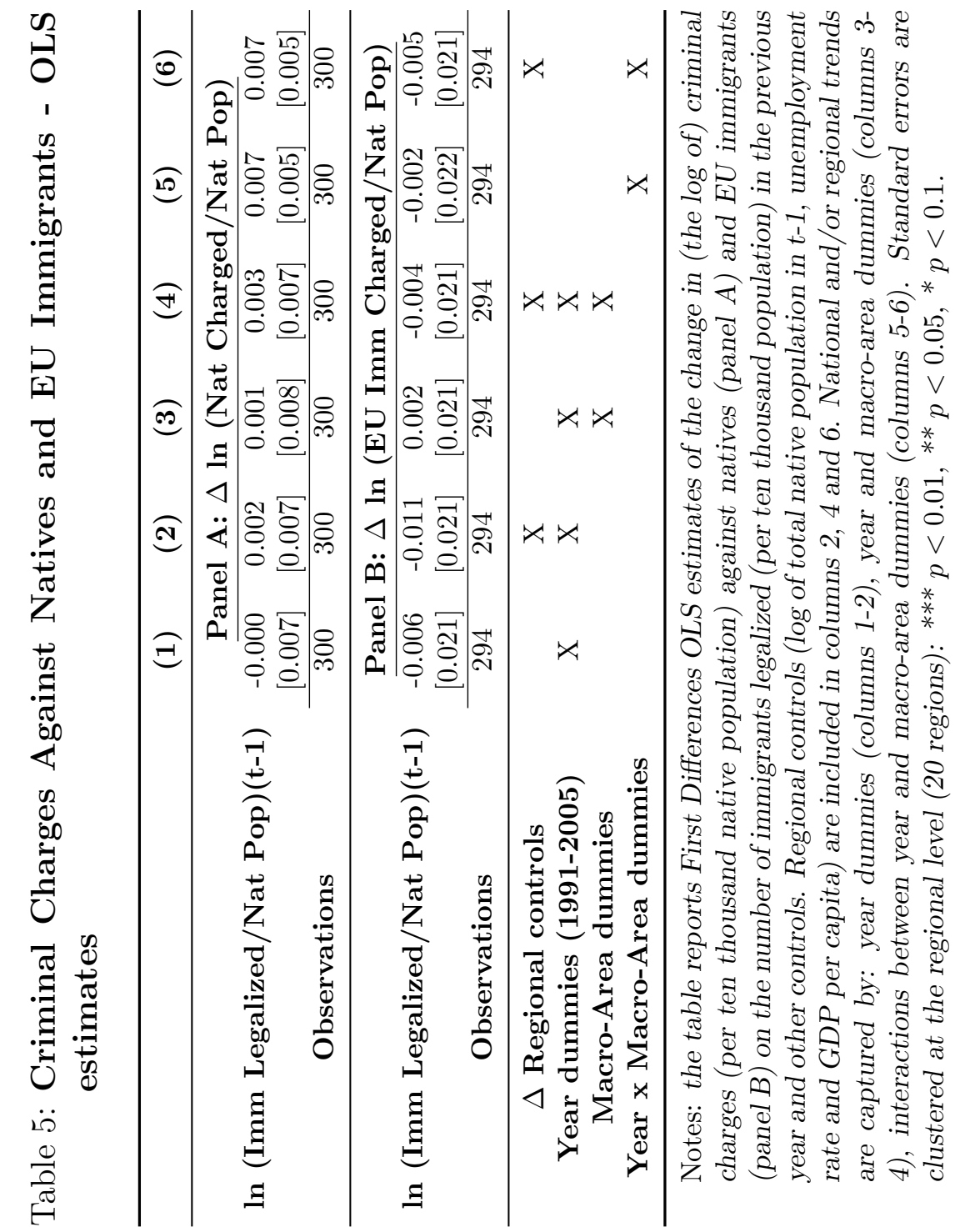




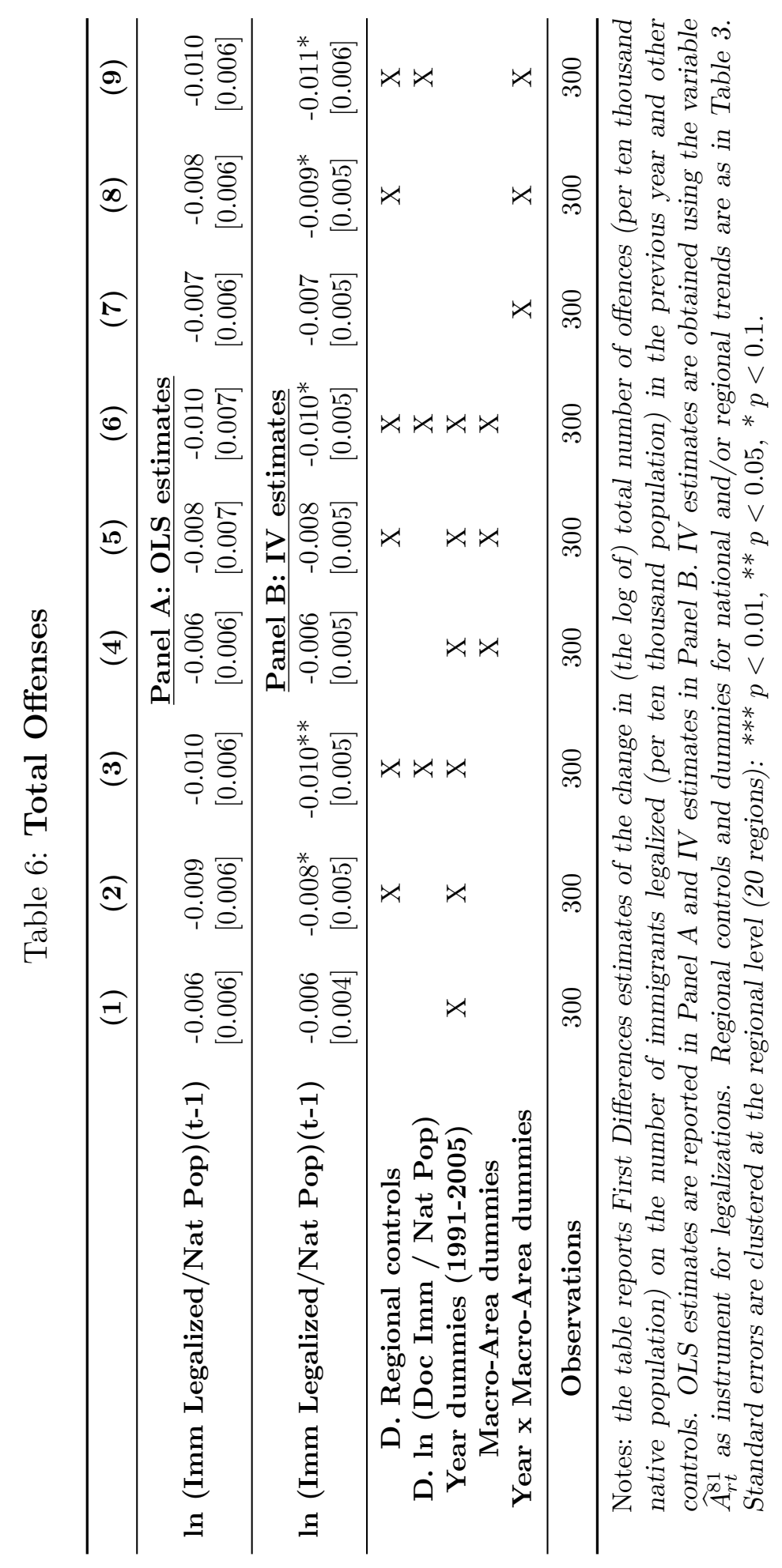




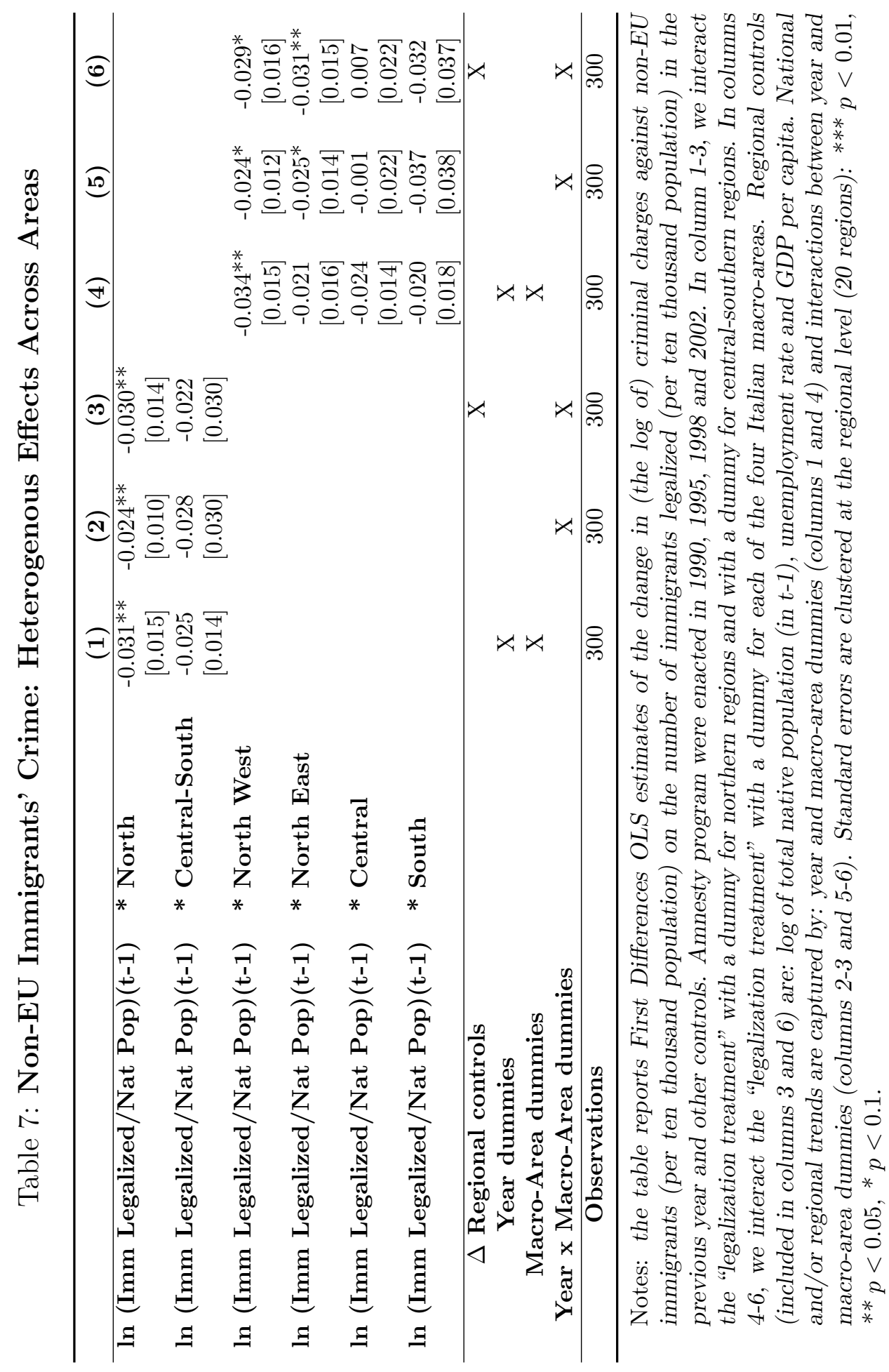




\section{A Online Appendix - Further Empirical Issues}

\section{A.1 Alternative IV strategies}

In order to test the robustness of our estimates to the use of alternative instruments, we develop two additional IV strategies.

First, we construct an instrument - defined as $\widehat{A}_{r t}^{90}$ - replacing the immigrants shares measured in 1981 with the 1990 ones. Ministry of Internal Affairs's records on residence permits across Italian provinces for all nationalities of immigrants resident in Italy are available since 1990. Employing 1990 rather than 1981 data, therefore, we can improve our instrument by using information on a wider set of nationalities. This improvement is especially important for predicting legalizations in more recent amnesties. The overlap between predominant nationalities in 1981 and top 20 countries of origin of legalized immigrants gradually shrinks over time, because new nationalities started migrating to Italy while flows from some of the first group of nationalities declined over time. This implies that our main instrument $\widehat{A}_{r t}^{81}$ is based on a progressively smaller number of nationalities. ${ }^{36}$ The drawback of using data from 1990, however, is that we should now worry about persistent shocks that may have influenced the distribution of both the immigrants in 1990 and the legalizations in later years. This concern is particularly salient for the first two amnesties we analyze. Here, we face a trade-off between having better data and potentially threatening the validity of our IV strategy.

Second, we develop an instrumental variable strategy - defined as $\widehat{A}_{r t}^{86}$ - that is exclusively based on the regional distribution of amnesty applications in the first legalization program that took place in 1986. In particular, we use the number of immigrants legalized in each Italian region with the 1986 amnesty as instrument for the legalizations granted in following amnesties. From one amnesty to the other, local economic shocks should change the relative attractiveness of regional labor markets for undocumented immigrants arriving in Italy and their incentives

\footnotetext{
${ }^{36}$ For instance, nine of the first twenty nationalities that were legalized with the 1990 amnesty were also among the major national communities residing in Italy in 1981. The number drops to four countries in the 2002 amnesty.
} 
to apply for legal status. While this latter variation is potentially endogenous in our regressions, the instrument we propose should isolate the component of exogenous variation that can be predicted based on past residential and amnesty application choices of undocumented immigrants. Our instrument is time invariant and we therefore interact it with amnesty year dummies. These interaction terms allow legalizations in 1986 to differentially predict the "legalization treatment" in each of the following amnesties. ${ }^{37}$ As before, the instrument is valid under the assumption that regional shocks are not too persistent.

\section{A.2 Other Regional Controls}

In our view, the other regional controls included in our regressions - i.e., resident population, unemployment rate, GDP per capita, share of documented immigrants - do not pose particular empirical issues. Nevertheless, throughout our empirical analysis, we will test the robustness of our main results by first presenting unconditional estimates of the impact of legalizations on immigrant crime and then by gradually adding regional controls. When conditioning on the resident population, we exclusively use the native population and lag it once, as natives may react to immigrant inflows by moving to other areas (although inter-regional migration is very low in Italy). The first lag of the native population is also used to normalize both immigrant crime and the "legalization" treatment. Local economic controls (unemployment rate and GDP per capita) are considered exogenous in our regression: as the number of individuals legalized is small relative to the native population (its average value in amnesty years is approximately 45 individuals for every ten thousand native residents; see Table 1), we exclude an effect of the "legalization treatment" on regional economic outcomes. ${ }^{38}$ The inclusion of the share of documented immigrants, however, is potentially more problematic. Although the documented stock shows independent variation with respect to the legalization programs - driven, for instance, by new legal entries and by return migration - the number of immigrants legalized and the

\footnotetext{
${ }^{37}$ This approach is analogous to the main IV strategy adopted in Dustmann et al. (2013).

${ }^{38} \mathrm{All}$ our findings are robust to using the first lag of regional unemployment rate and GDP per capita. Results can be provided upon request.
} 
changes in the documented stock are highly and positively correlated in the years immediately following an amnesty. Obviously, regions where larger numbers of immigrants obtain legal status experience larger increases in the stock of documented immigrants. These amnesty-driven mechanical increases in the documented immigrant population make us wary of conditioning on this variable in our regressions, and we therefore include this control only in some of the specifications. If both immigrant crime and the number of legalizations are positively correlated with the stock of legal migrants, leaving the latter variable in the error term will potentially generate an upward bias in our estimates of the impact of legalization on immigrant crime. As this latter parameter is expected to be negative, we would therefore estimate a lower bound of the effect of interest.

\section{A.3 Clustering of standard errors}

Throughout our empirical analysis, we cluster the standard errors at the regional level. While allowing for intra-region serial correlation in shocks seems the most sensible approach to get correct inference in our setting, one may worry that the small number of clusters (twenty) may lead to a downward bias in estimating the standard errors (Bertrand et al., 2004). As a matter of fact, the asymptotic justification for inference with cluster-robust standard errors assumes that the number of clusters goes to infinity. Although there is no recognized rule-of-thumb to establish when the clusters are "too few", twenty clusters may be close to that worrying threshold (although the issue is less problematic when the panel is balanced, as it is in our case; see Cameron and Miller, 2015). Cameron et al. (2008) recommend using the cluster-robust (Huber-White) variance estimator but prescribe using bootstrap when there are few clusters. In particular, they suggest using wild cluster bootstrap to improve finite-sample inference (see Cameron and Miller, 2015, for a detailed discussion of this method). In Appendix Table A 2, we report again the OLS estimates of the "legalization treatment" shown in Panel A of Table 3 (excluding those conditional on share of documented immigrants). We compare the 
p-values obtained by clustering the standard errors with those produced by implementing wild cluster bootstrap (using an increasing number of bootstrapping repetitions: 500, 1000, 2000 and 5000). ${ }^{39}$ Remarkably, bootstrapped p-values are not systematically larger than those obtained from "simple" clustering (actually, they tend to be smaller in four columns out of six) and the level of significance of the estimates is identical for the two procedures in all cases. Overall, estimates in Appendix Table A 2 suggest that in our setting having twenty clusters does not affect the correctness of our inference.

\section{A.4 Spatial Analysis}

Our empirical analysis is based on the twenty administrative Italian regions (i.e. NUTS 2). These are relatively large geographical units, since Italy as a whole has an area of more than 300 thousand km. Nevertheless, we may still worry that ignoring spatial lags or spatial dependence in the error term may lead to biased estimates or reduced efficiency, respectively (LeSage and Pace, 2009). In this section, we test for the presence of spatial autoregression or autocorrelation across regions and check whether our estimates are affected by takings these empirical aspects into consideration.

In order to carry out our spatial analysis, we start by constructing an inverse-distance matrix for all twenty Italian regions. We use the geographical coordinates of each region capital city to compute distances across regions. Since our study focuses on migration and crime - that are both phenomena highly concentrated in urban centres - this choice seems preferable to using region centroids. We use the haversine distance measure, as computed by the Stata spmat command (see Drukker et al., 2013). The average distance between capitals of different Italian regions is approximately $330 \mathrm{~km}$. In order to exclude unreasonable spatial influences between regions that are extremely far from each other, we truncate this matrix at three different thresholds, constructing alternative spatial weighting matrices. In particular, we set equal to

\footnotetext{
${ }^{39}$ Wild cluster bootstrap p-values are obtained using the STATA command cgmwildboot, written by Judson Caskey.
} 
zero the inverse distances of regions whose capitals are more than $330 \mathrm{~km}, 250 \mathrm{~km}$ and $150 \mathrm{~km}$ apart. Obviously, the number of links (i.e. "neighbours") defined by each weighting matrix is increasing in the chosen threshold. When the maximum distance is set to $330 \mathrm{~km}$, there is only one region (Sardinia) without any link to other regions and there are two regions with 11 links. The maximum number of links decreases to 8 and to 4 when the maximum distance is constrained to be below 250 and $150 \mathrm{~km}$, respectively.

Appendix Table A 6 presents estimates obtained from our spatial analysis. We regress changes in (the log of) criminal charges (per ten thousand native population) on the number of immigrants legalized (per ten thousand population) in the previous year. We estimate two spatial models with Quasi-Maximum Likelihood: a Spatial Autoregressive Model (SAR) in panel A and a Spatial Error Model (SEM) in panel B. ${ }^{40}$ We denote with $\rho$ the coefficient on the spatial lag and with $\lambda$ the coefficient for the spatial error. We use the alternative spatial weighting matrices $W$ obtained by giving weight zero to regions that are more than $330 \mathrm{~km}$ (columns 1-3), $250 \mathrm{~km}$ (columns 4-6) and $150 \mathrm{~km}$ (columns 7-9) apart. Appendix Table A 6 shows that - irrespectively of the spatial weighting matrix used - the spatial terms are generally not significant. Moreover, our estimates of the impact of legalizations on immigrant crime are not affected by allowing for spatial lags and spatial correlation. These findings suggest that spatial dependence is not relevant in our context.

\footnotetext{
${ }^{40}$ Both models are estimated using the Stata xsmle command (see Belotti et al. 2017).
} 


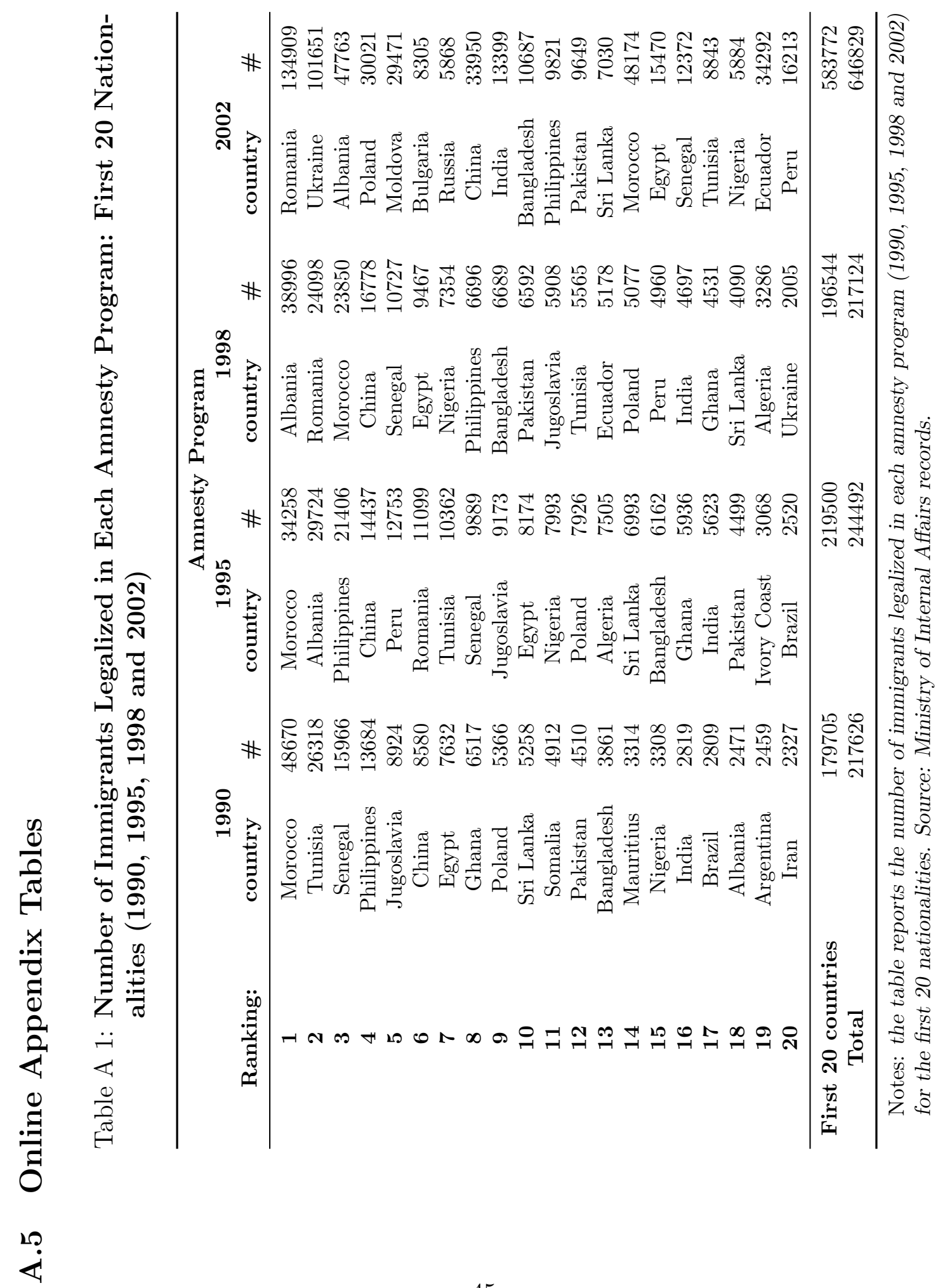




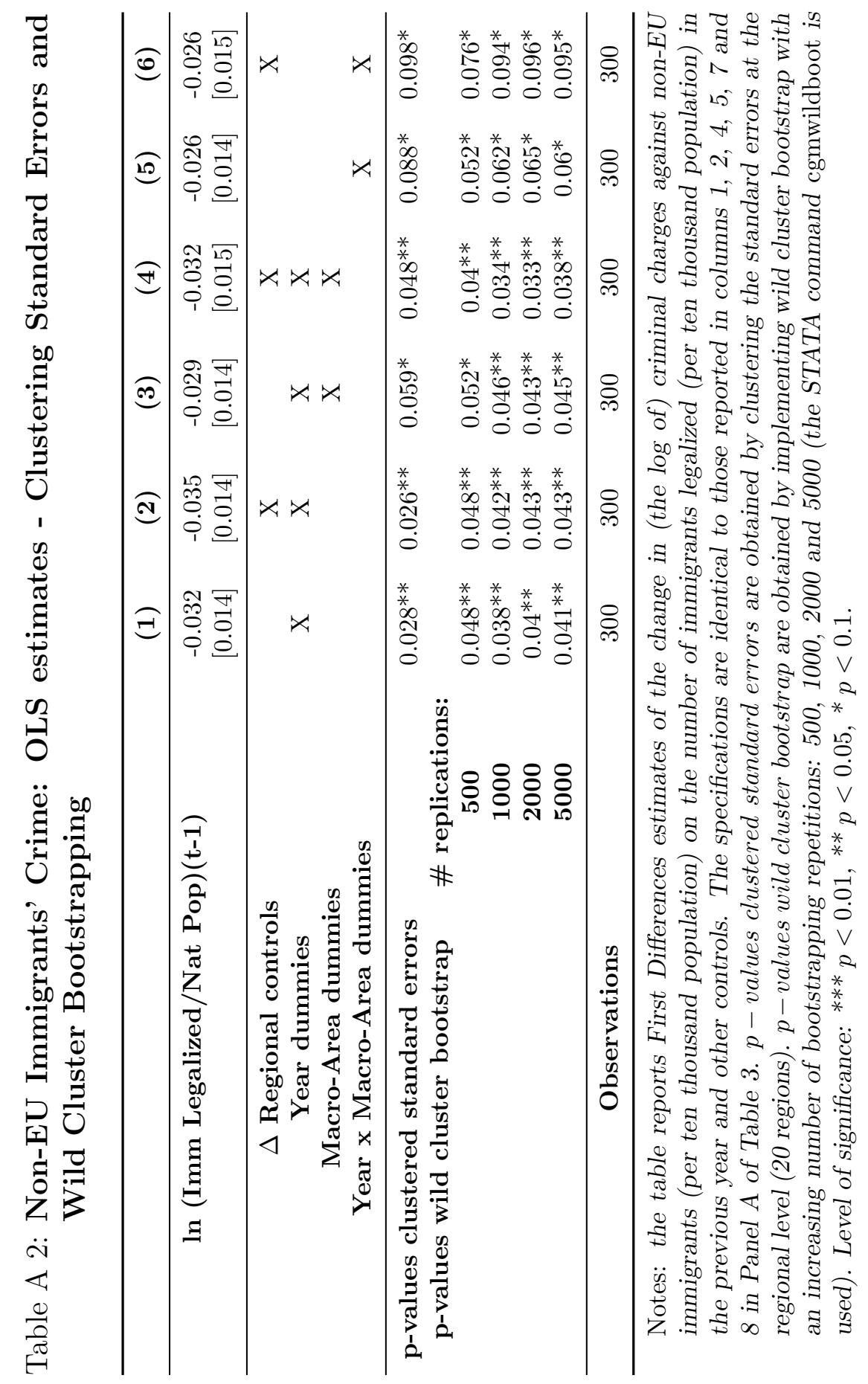




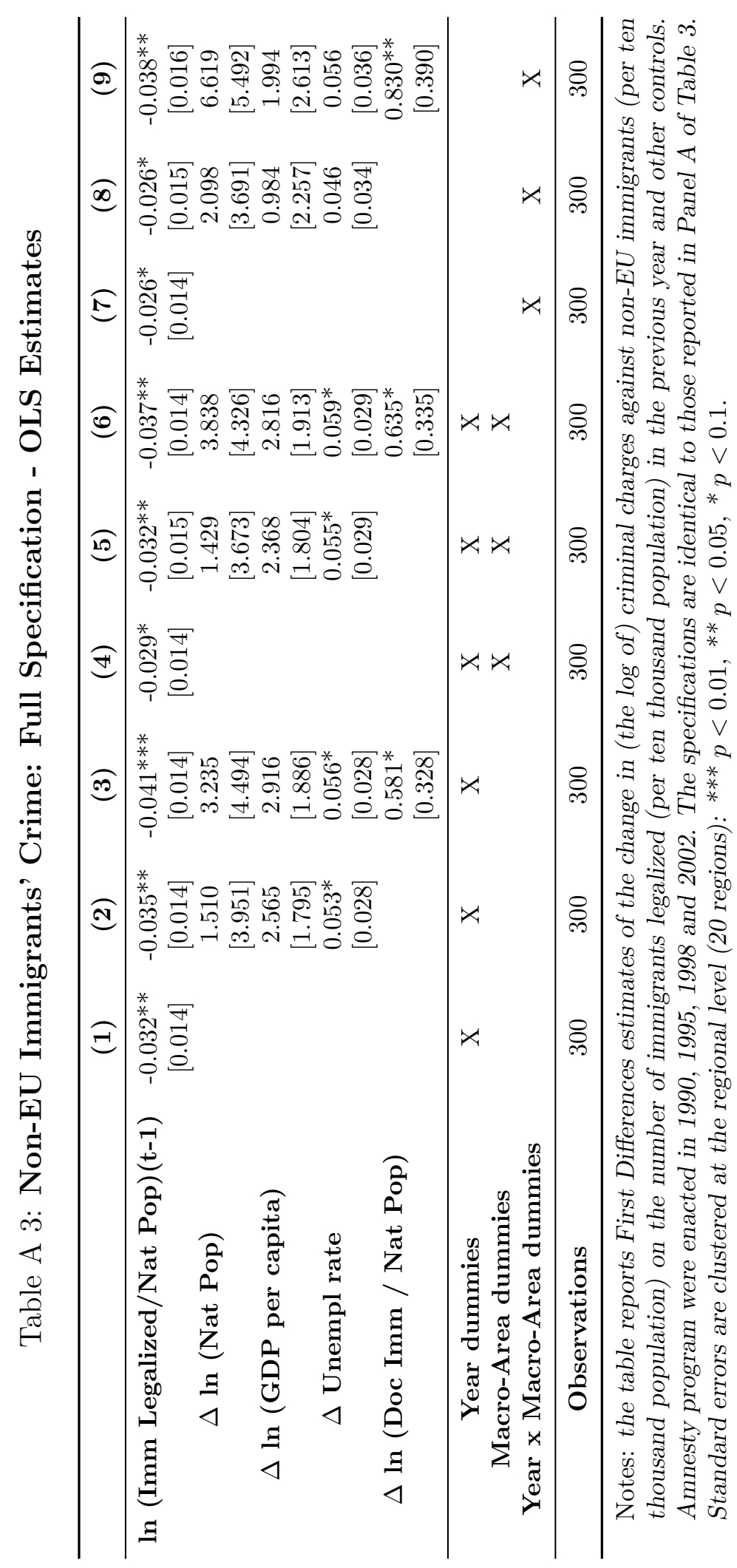




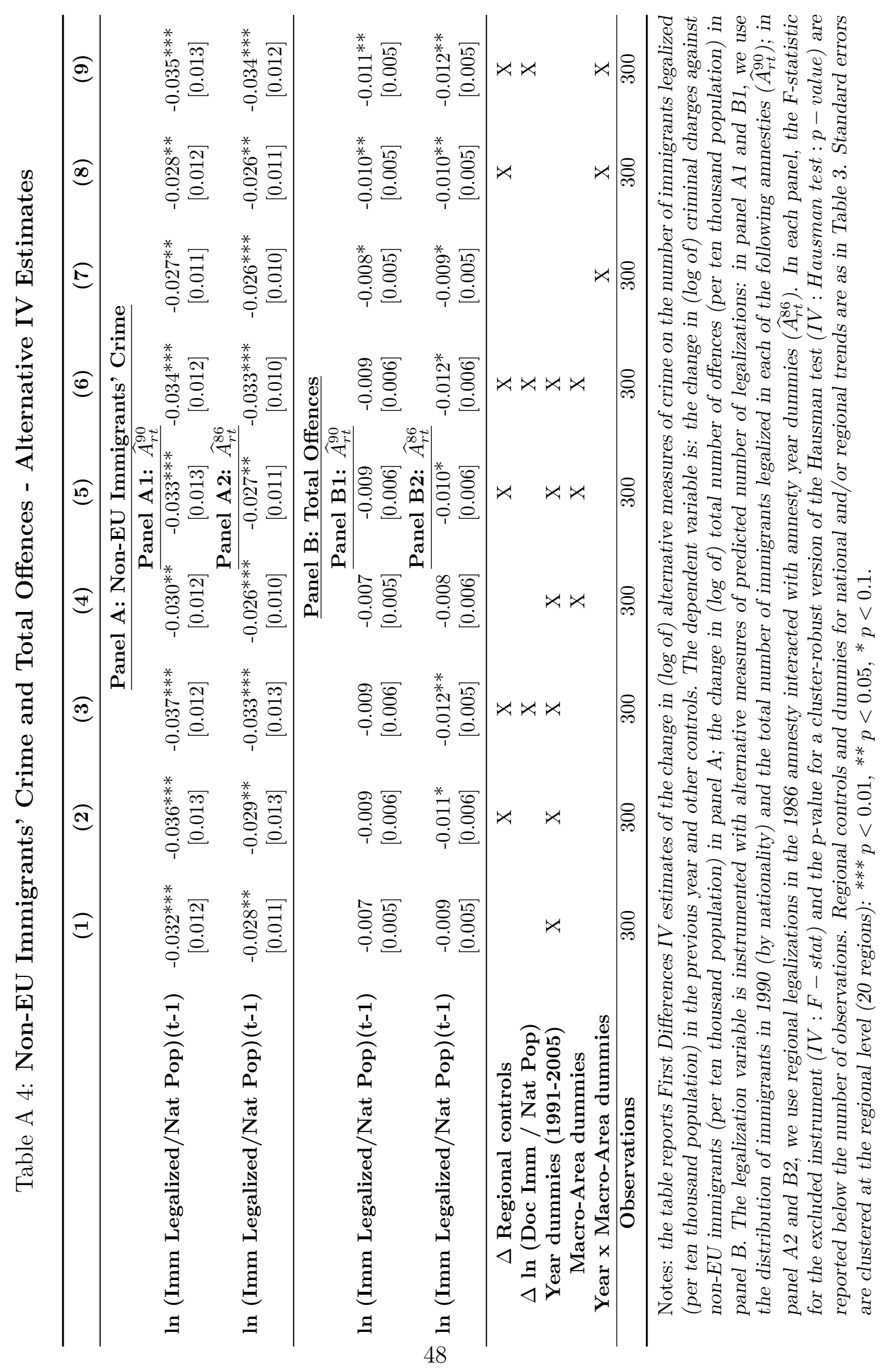




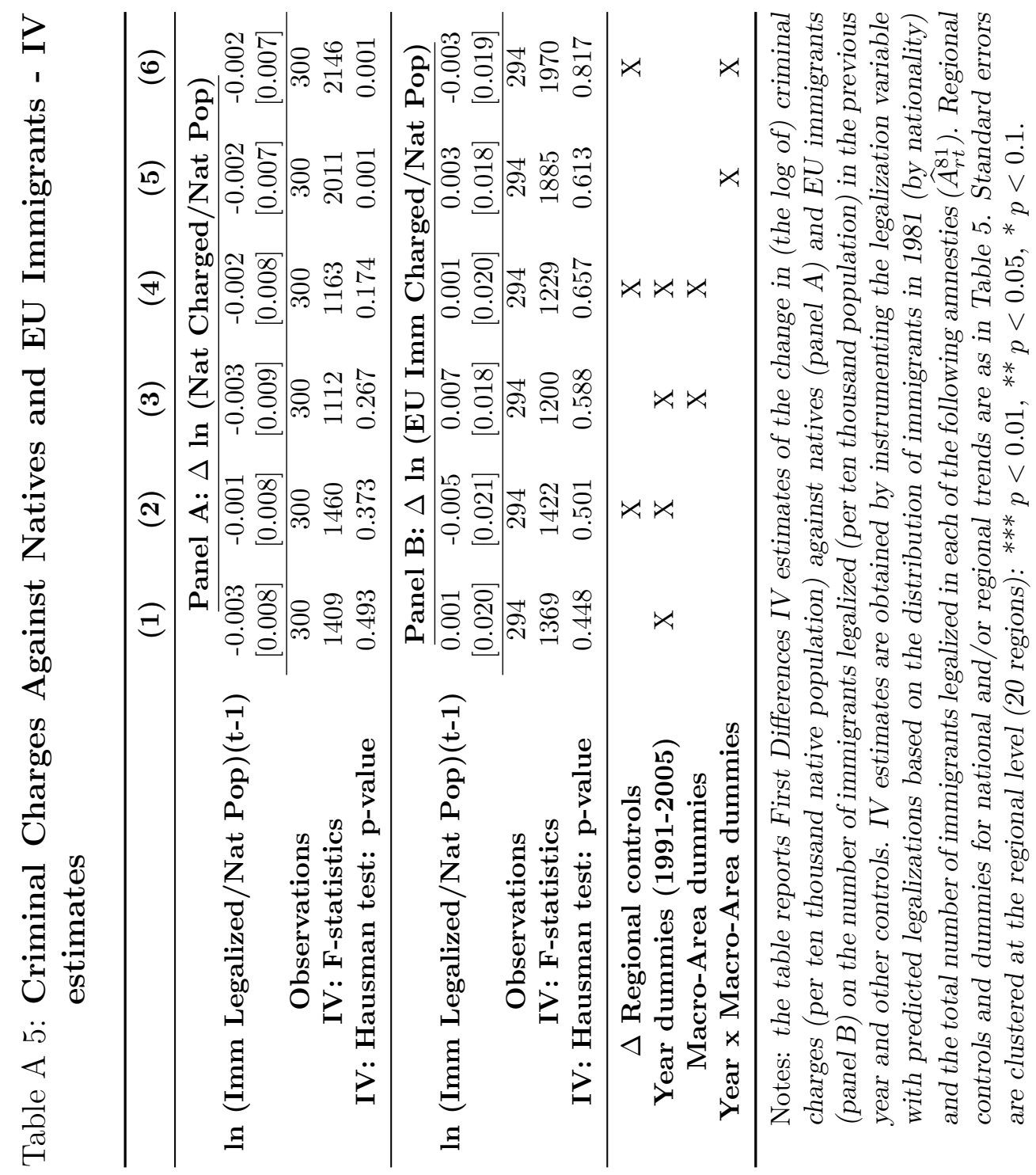




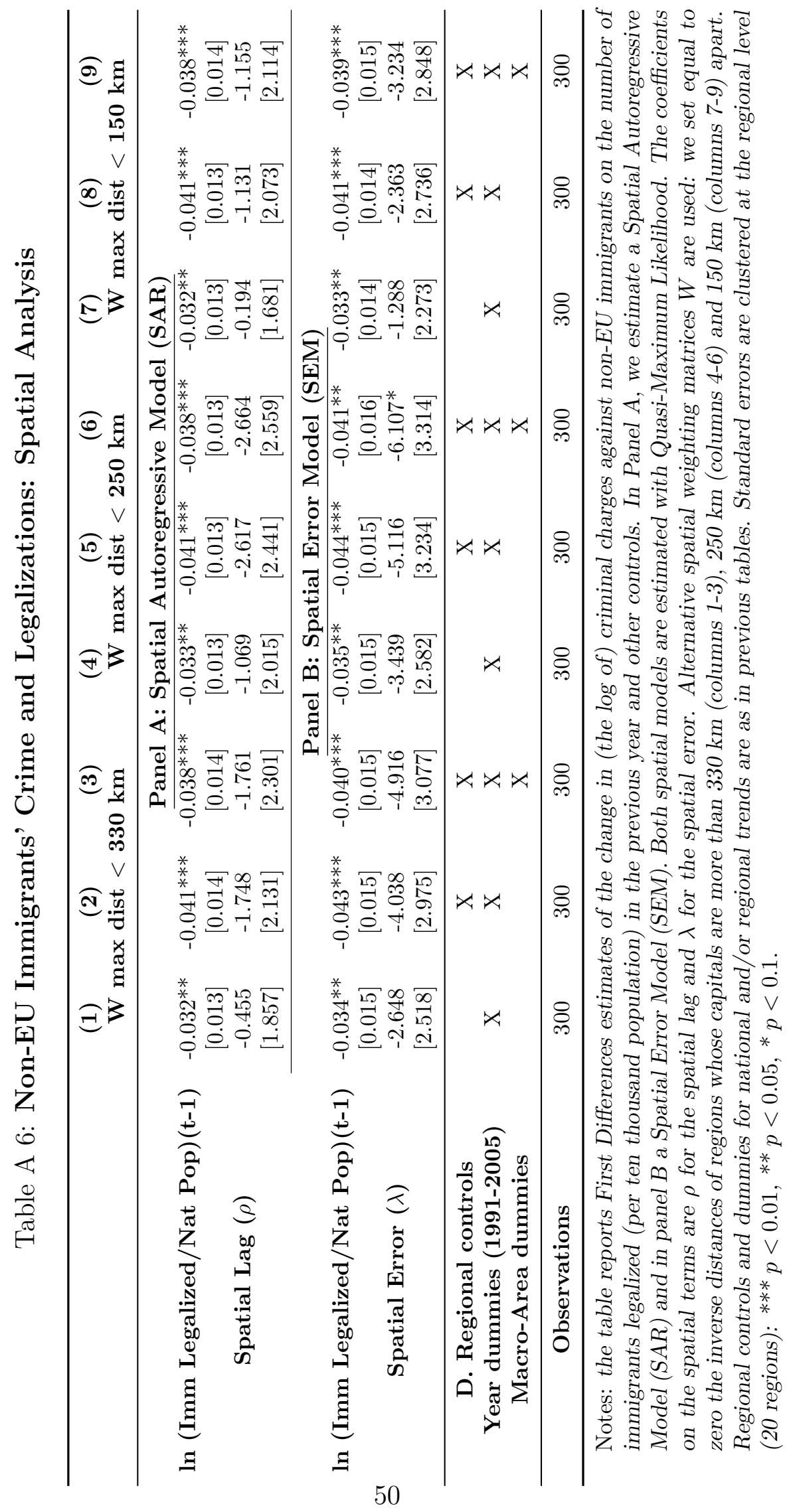

